Georgia State University

ScholarWorks @ Georgia State University

$12-4-2006$

\title{
Investigating the Utility of the Film War Zone as a Component of a Street Harassment Prevention Program
}

Doyanne A. Darnell

Follow this and additional works at: https://scholarworks.gsu.edu/psych_theses

Part of the Psychology Commons

\section{Recommended Citation}

Darnell, Doyanne A., "Investigating the Utility of the Film War Zone as a Component of a Street Harassment Prevention Program." Thesis, Georgia State University, 2006.

doi: https://doi.org/10.57709/1061205

This Thesis is brought to you for free and open access by the Department of Psychology at ScholarWorks @ Georgia State University. It has been accepted for inclusion in Psychology Theses by an authorized administrator of ScholarWorks @ Georgia State University. For more information, please contact scholarworks@gsu.edu. 
INVESTIGATING THE UTILITY OF THE FILM WAR ZONE AS A COMPONENT

\title{
OF A STREET HARASSMENT PREVENTION PROGRAM
}

by

DOYANNE ASPEN DARNELL

Under the Direction of Sarah L. Cook

\begin{abstract}
Street harassment, the sexual harassment by strangers in public places, is a common experience shared by many women and has been linked with other forms of sexual victimization. The negative impact of street harassment, such as fear and behavior to avoid being harassed, points to the need for preventing the behavior. This study sought to determine whether the documentary-style film War Zone may be effective in impacting men's attitudes toward street harassment, and whether the effectiveness of the film would depend on men's hostility toward women and level of peer acceptance for street harassment. Findings do not support the effectiveness of War Zone as a component of street harassment prevention. However, the data does suggest that endorsement of hostile attitudes toward women predicts a lack of empathy, and that endorsement of hostile attitudes toward women, a lack of empathy, and peer acceptance of street harassment predict acceptance of street harassment.
\end{abstract}

INDEX WORDS: Street harassment, sexual victimization, prevention, victim empathy, hostile attitudes toward women, peer attitudes 


\title{
INVESTIGATING THE UTILITY OF THE FILM WAR ZONE AS A COMPONENT \\ OF A STREET HARASSMENT PREVENTION PROGRAM
}

\author{
by \\ DOYANNE ASPEN DARNELL
}

A Thesis Submitted in Partial Fulfillment of the Requirements for the Degree of Master of Arts

in the College of Arts and Sciences

Georgia State University 
Copyright by

Doyanne Aspen Darnell 2006 
INVESTIGATING THE UTILITY OF THE FILM WAR ZONE AS A COMPONENT

OF A STREET HARASSMENT PREVENTION PROGRAM

by

DOYANNE ASPEN DARNELL

Major Professor: $\quad$ Sarah Cook

Committee: James Emshoff

Tracie Stewart

Electronic Version Approved:

Office of Graduate Studies

College of Arts and Sciences

Georgia State University

December 2006 
Dedicated to the women in my research group. 
I would like to thank my committee for their feedback and suggestions on my project, Sarah Cook for her support, enthusiasm, and in-depth review of this paper, my colleagues for their help throughout my project, Adam Darnell for his support and help with data collection, and to my family and friends for always encouraging me. 
TABLE OF CONTENTS

ACKNOWLEDGEMENTS................................................ $\quad \mathrm{v}$

LIST OF TABLES........................................................ viii

LIST OF FIGURES...................................................... xi

\section{CHAPTER}

$1 \quad$ INTRODUCTION................................................... 1

Street Harassment as a Form of Sexual Victimization ...................... 3

Preventing Sexual Victimization........................................................ 10

The Present Study............................................................................. 16

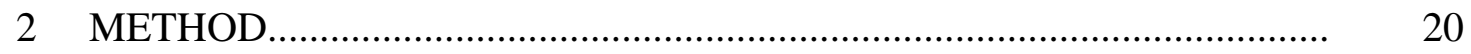

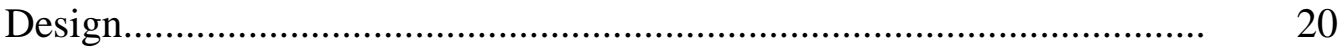

Participants............................................................................. 20

Experimental Conditions.................................................................. 21

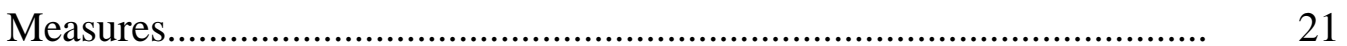

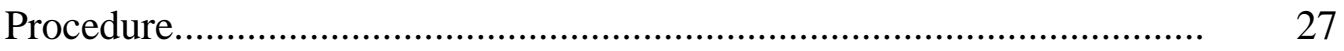

Planned Statistical Analyses.................................................................. $\quad 29$

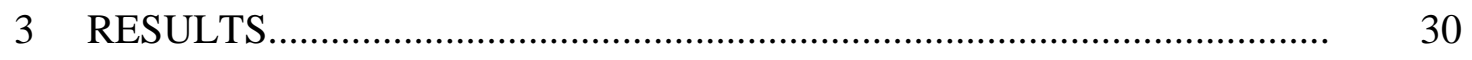

Question 1 ........................................................................................ $\quad 31$

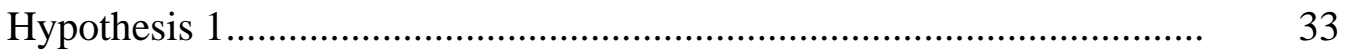

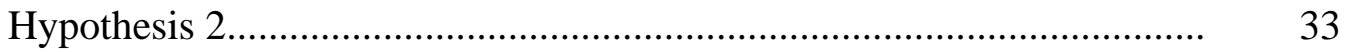

Supplementary Analyses..................................................................... $\quad 35$

Exploratory Analyses.................................................................... 36

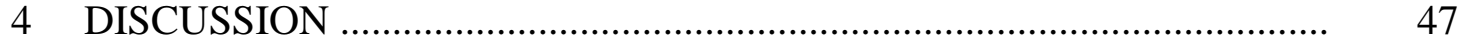




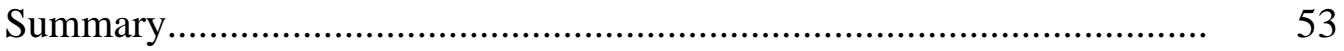

REFERENCES............................................................. 55

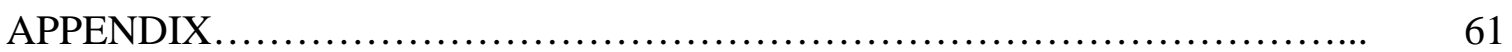

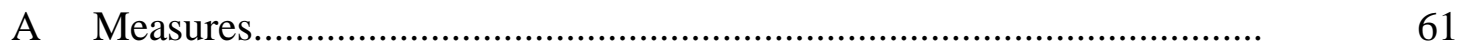




\section{LIST OF TABLES}

TABLE 1: Means and Standard Deviations for War Zone $(n=40)$ and Under Antarctica Ice $(n=42)$, and Variable Correlations with Film Condition $(N=82) \ldots \quad 30$

TABLE 2: Appreciation for the Film............................................................. 31

TABLE 3: Summary of Hierarchical Regression Analyses Predicting Forms of

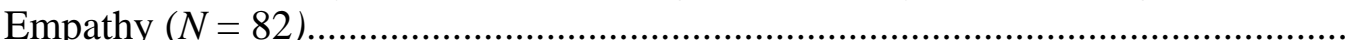

TABLE 4: Summary of Hierarchical Regression Analyses Predicting Acceptance

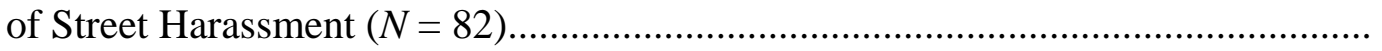

TABLE 5: Summary of Hierarchical Regression Analyses Predicting Forms of Empathy and Acceptance $(\mathrm{N}=82)$

TABLE 6: Percentage of Men Who Rated Acceptance and Peer Acceptance Items as Acceptable to Some Degree $(N=82)$....

TABLE 7: Intercorrelations Between Variables.

TABLE 8: Summary of Exploratory Moderation Analyses $(N=82)$......

TABLE 9: Intercorrelations between Hostile and Benevolent Sexism Based on Levels of Hostility Toward Women and Sexism $(N=81)$

TABLE 10: Men’s Responses to the Question “Describe What This Movie is About” $(n=40)$ 


\section{LIST OF FIGURES}

FIGURE 1: Logic Model for War Zone's Impact on Attitudes Toward Street

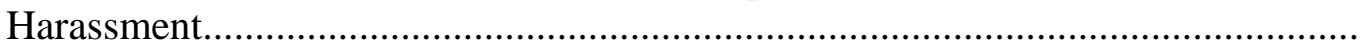

FIGURE 2: Category Frequency for Appreciation for the Film War Zone ( $n=$ 40)

FIGURE 3: Interaction Effect between Hostile Sexism and Film Condition on

Benevolent Sexism... 


\section{INTRODUCTION}

Street harassment, the sexual harassment by strangers in public places, is an experience shared by so many women that it has become an expected part of womanhood (Bowman, 1993; Gardner, 1995). One study estimates that $77 \%$ of Canadian women have experienced street harassment in their lifetime (Lenton, Smith, Fox, \& Morra, 1999). A variety of behaviors fall into the category of street harassment including catcalls, wolf whistles, sexual gestures and comments. Street harassment shares defining aspects with sexual assault: the targets are most often women, initiators are most often men, and targets are forced to endure the behavior of the initiator, which is often degrading, objectifying and threatening (Bowman, 1993; Lenton et al., 1999; Quina, 1990). Although most would place street harassment behaviors at the less severe end of the continuum, some experiences of street harassment can be assaultive.

Despite the prevalence of street harassment and its conceptual link to other forms of victimization, such as sexual harassment and assault, little empirical research exists on it. The work that has been done suggests that street harassment induces fear, anger, and shame, and leads to changes in behavior to avoid future harassment that may be limiting (Gardner, 1995; Lenton et al., 1999; MacMillan, Nierobisz, \& Welsh, 2000). Virtually no methods of prevention have been developed. I have identified possible reasons for this inattention. First, inattention may result because in contrast to sexual harassment and assault, street harassment is so common it is considered normative, and at most annoying, but not problematic. Second, even if street harassment is considered problematic, it is not 
perceived as actually harmful, and thus, not in need of prevention efforts. Third, women and men hold contradictory perspectives about the behavior. For instance, some men think street harassment is complimentary and that women enjoy the behavior. In fact, some women do find the behavior complimentary even though others do not (Gardner, 1995).

The overall goal of this study is to further the understanding of street harassment and explore potential avenues for prevention. The specific purpose is to investigate whether the film, War Zone (Hadleigh-West, 1998), impacts men’s attitudes toward street harassment. War Zone is a documentary style film in which a woman confronts men who engage in street harassment toward her and other women. She uses a camera to record the men's reactions to her confrontation and their thoughts about street harassment. The study has three specific aims: 1) document men’s opinions of War Zone, 2) determine whether men who view War Zone report more empathy for women who experience street harassment than men who do not view War Zone, and whether this relationship depends on men's reported level of hostility toward women and sexist beliefs, and 3) determine whether men who view War Zone report less acceptance of street harassment than men who do not view War Zone, and whether this relationship depends on men’s reported level of empathy and men's reported peer acceptance of street harassment. These aims are informed by the sexual assault and sexual harassment literature that suggests common individual and contextual variables related to sexual victimization perpetration, as well the evaluation literature on sexual assault and sexual harassment prevention. 


\section{Street Harassment as a Form of Sexual Victimization}

A review of the literature on sexual victimization suggests theoretical and empirical links between all forms of sexual victimization that can inform the nature of street harassment and possible avenues for street harassment prevention.

\section{Six Dimensions Underlying Sexual Victimization}

Six dimensions that characterize sexual victimization demonstrate the theoretical link between street harassment and other forms of sexual victimization. Some of these characteristics have been empirically investigated and support the link. They include: 1) power dynamics, 2) cultural myths and attitudes, 3) costs to the survivor, 4) offender characteristics, 4) gender roles and relationships, and 5) emotional reactions of victims (Quina, 1990). This study addresses three of these dimensions: a) gender roles and relationships, b) offender characteristics, and c) emotional reactions of victims, primarily because they are highlighted in the film, but also because they have been empirically explored as causal factors of sexual victimization and thus may be implicated in street harassment.

\section{Gender Roles and Relationships}

Gender roles are comprised of both stereotypes, or ideas about how men and women typically are, and norms, or ideas about how men and women should be. These culturally prescribed roles promote male dominance over women thereby supporting perpetration of sexually aggressive behavior in which men assert their dominance by forcing women to endure a sexual behavior. Likewise, street harassment is an intrusive behavior in which the perpetrator may assert his dominance by forcing a woman to engage with him on the street in a sexual way. 
Sexism. Sexism is a form of prejudice that is based on beliefs about men, women, and their appropriate roles in society. This study looks only at sexist attitudes toward women. Glick \& Fiske (1996) identify the overarching category of ambivalent sexism, which is broken into hostile sexism (apparently negative and prejudicial beliefs about women, including that women seek to gain power over men) and benevolent sexism (attitudes that idealize women based on traditional stereotypes of women as particularly moral, better at interpersonal relationships, and something to be cherished and placed on a pedestal).

Ambivalent sexism is related to perpetration of sexual victimization; however, most of this relationship seems to be carried by hostile sexism (Abbey, McAuslan, Zawacki, Clinton, \& Buck, 2001; Begany \& Milburn, 2002; Caron \& Carter, 1997; Forbes, Adams-Curtis, \& White, 2004; Murnen, Wright, \& Kaluzny, 2002). For example; both benevolent and hostile sexism were related to sexual harassment in a study of undergraduate men’s and women’s attitudes toward sexual harassment (Russell \& Trigg, 2004); however, the correlation between hostile sexism and tolerance for sexual harassment was much higher than for benevolent sexism and tolerance.

Benevolent sexism appears to relate more strongly to justifications for sexual victimization than to perpetration (Abrams, Viki, Masser, \& Bohner, 2003). Characteristics associated with benevolent sexism are typically attributed to women who fit traditional stereotypes and who do not challenge the social power structure that defines men as more competitive and status-seeking. Benevolent sexism suggests that women who act in such a traditional (i.e. pure, moral, and lower status-seeking) manner will be rewarded with respect and protection (Glick \& Fiske, 2001). People who adhere to 
benevolently sexist beliefs may be more likely to blame the victim of sexual

victimization for her predicament, particularly if she is seen as having stepped outside of her prescribed social role.

Sexism is expected to play a similar role in the perpetration of street harassment. Sexist views about women, particularly hostile views, may motivate men to harass women on the street by promoting a sense of entitlement and desire to dominate women.

Hostility toward women. Hostility toward women appears to promote and justify the use of violence or exploitative behavior (Marshall \& Moulden, 2001). Malamuth and colleagues (1995) delineate the concept of "hostile masculinity" which they assert promotes sexual aggression when accompanied by an impersonal attitude toward sex. Hostile masculinity, which describes men with 1) an insecure, defensive, hypersensitive, and hostile-distrustful orientation, particularly toward women, and 2) gratification from controlling or dominating women, is empirically related to sexual aggression (Malamuth, Linz, Heavey, Barnes, \& Acker, 1995).

Convicted male rapists have indicated greater hostility toward women than male non-sexual offenders (Marshall \& Moulden, 2001), and among male university students, hostility toward women is more strongly related to sexual coercion than other types of attitudes about women (e.g., sexism) and attitudes about sexual assault (e.g., rape myth acceptance; Forbes et al., 2004). Further, the results of a meta-analysis of 39 studies relating masculine ideology to sexual aggression found that hostile masculinity was most robustly associated with sexual aggression among numerous other predictors, including power over women, hypermasculinity, rape myth acceptance, attitudes toward women's 
rights, adversarial sexual beliefs, sex role conservatism, and sex role stereotyping (Murnen et al., 2002).

Hostility toward women may underlie men's harassment of women on the street because it is another way in which men can gain a sense of control and dominance over women whom they may perceive as easy targets and who may otherwise be threatening to their masculinity.

\section{Offender Characteristics}

Offender characteristics are attributes that perpetrators share across the various types of sexual victimization. This study will examine attitudes about gender roles and stereotyping (previously discussed), peer group support for sexual victimization, and empathy toward victims.

Peer groups. Peer support for sexually victimizing behaviors is an important predictor of men's acceptance of sexual victimization (Abbey et al., 2001; DeKeseredy \& Kelly, 1995; Quinn, 2002). Research demonstrates that social groups, such as athletic teams and fraternities, demonstrate greater adherence to rape-supportive attitudes, such as rape-myths, than do unaffiliated groups of students, and that groups at high risk for sexual aggression differ from low-risk groups in their hostility and negative attitudes toward women, as well as levels of peer support of sexual aggression (Boeringer, 1999).

Street harassment often occurs in a context in which men are in the company of other men, and is encouraged by a group dynamic in which men gain a sense of camaraderie with other men based on a shared sense of masculinity (Gardner, 1995). From a qualitative study in which 43 primarily Caucasian men were interviewed about the practice of "girl watching” (the sexual evaluation of women), Quinn (2002) asserts 
that men often evaluate women sexually with other men in order to socially bond with each other. She observes that the men watch and comment sexually on women as a fun way to declare their masculinity. With this purpose of girl watching in mind, she likens the behavior to sexual joke telling.

Other researchers have investigated the connection between sexual joke telling and peer influence. In two studies of sexual joke telling with 81 undergraduate, primarily Caucasian men, Angelone, Hirschman, Suniga, Michael, Armey, and Armelie (2005) demonstrate that peer behaviors and attitudes affect men's behavior. In their studies, men who were exposed to men who either engaged in high sexual joke telling toward an unknown woman or expressed sexist attitudes toward women, themselves engaged in more sexual joke telling toward an unknown woman than men who had not been exposed to such peer behavior or attitudes. This study takes the perspective that men will be influenced by the behavior and attitudes of their peers with regards to street harassment.

Empathy. Empathy is defined in a number of ways throughout the psychological literature. Generally, empathy is understood to have both a cognitive and emotional component, although definitions of empathy vary in the emphasis placed on one or the other aspect. For instance, one definition characterizes empathy as the ability to take another person's perspective and understand an experience from their point of view (Davis, 1994), which clearly addresses only the cognitive component of empathy.

Marshall, Hudson, Jones, and Fernandez (1995) delineate a four staged process of empathy, which includes the ability to 1) discern another's emotional state, 2) see the person's situation from their point of view, 3) experience what the person is feeling, and 4) choose what to do based on this empathic perception. In this model, empathy includes 
both a cognitive and emotional component, and may lead to a particular behavior. However, the pathway between empathy and behavior has not been explained.

Finally, empathy may be viewed as an entirely emotional experience. Baston, O'Quin, Fultz, Vanderplas, and Isen (1983) postulate that people may experience one of two emotions as a consequence of witnessing a person’s suffering; one emotion characterized by feelings of distress and the other characterized by sympathy for the other person. In this view, only the sympathy for the other person is considered empathy. In their view, the two vicarious emotional responses to witnessing another person's suffering are distinct and lead to distinct behavioral motivations. Specifically, their research indicates that personal distress is more likely to influence behavior intended to reduce the distress the participant is feeling (egoistic motivation) whereas empathy motivates the participant to reduce the distress another person may be feeling (altruistic motivation).

A lack of empathy for victims in particular, as opposed to a lack of empathy in general, is related to sexual assault and sexual harassment perpetration (Marshall et al., 1995; Marshall \& Moulden, 2001; Quinn, 2002). For instance, compared to incarcerated male nonsexual offenders, sexual offenders displayed the least amount of empathy toward their victim's but displayed an equal amount of empathy as nonsexual offenders toward an unknown female victim of sexual assault (Fernandez \& Marshall, 2003).

Quinn (2002) suggests that men may actually suppress empathic abilities toward women who are sexually harassed. Based on a qualitative study, she asserts that men actually ignore women's perceptions of these behaviors and deny the deleterious effects of sexually evaluating women (i.e., "girl watching”) in an effort to achieve masculine 
prescriptions that require them to avoid taking a woman's perspective. This work suggests that perpetrators of street harassment likely have deficits in their ability to correctly perceive women's emotional experience of street harassment and may have difficulty feeling what women who experience street harassment are feeling. This study adopts the perspective that both cognitive and affective empathy will be involved in street harassment.

\section{Emotional Reaction of Victims}

In order to be empathic, perpetrators must have an accurate sense of the victim’s emotional reactions. Sexual harassment and sexual assault are both related to a variety of psychological consequences for women, including: depression, anxiety, increased risk for substance abuse, fear, guilt and shame. Physical sequelae include: injury from the assault (including transmission of disease), chronic pain, headaches, irritable bowel syndrome, and other stress-related health effects. Further, these experiences often result in missed work, and decreased work enjoyment and performance (Koss, Goodman, Browne, Fitzgerald, Keita, \& Russo, 1994; O'Donohue, Downs, \& Yeater, 1998).

Research on street harassment suggests that it has a number of negative emotional impacts. In Gardner’s (1995) qualitative investigation into street harassment with 293 women, only 9 did not see street harassment as “troublesome.” Gardner reported that women experience various emotional reactions such as fear, guilt, and feeling bad, although she did not systematically record women's emotional reactions. Gardner also noted that all the women in her study employed at least one strategy to deal with future instances of street harassment, indicating that the behavior has a negative impact on women and their lives, which they attempt to avoid. For instance, 65 women, half 
minority and half white, reported making a "notable life decision on the basis of suspected or actual harassment in a public place”.

In a study of Canadian women, Lenton et al. (1999) identified a number of emotional effects of harassment. The authors asked 1,786 participants to recall their most upsetting experience with public harassment (i.e. street harassment) followed by openended questions asking participants how they felt at the time of the incident as well as how they feel currently about the incident. Three-quarters of the women said that fear was their initial feeling, 20\% reported feeling angry, and 7.4\% reported feeling violated. Importantly, $19.3 \%$ reported that they still feel angry or upset about the incident, which may have occurred many years in the past. These statistics suggest that street harassment often has immediate negative consequences for many women, and long-term negative consequences for some women. It is important to note that the behavior does not need to have immediate or long-lasting negative impacts on all women for it to be problematic and worth preventing.

\section{Preventing Sexual Victimization}

The degree of shared characteristics between sexual harassment, sexual assault, and street harassment suggests that some features of sexual assault and harassment prevention interventions may hold promise for the prevention of street harassment. Sexual harassment and sexual assault prevention programs primarily focus on two goals: educating people on what constitutes sexual harassment and sexual assault (i.e. psychoeducation), and changing intermediate outcomes that are theoretically and empirically related to perpetration such as, victim empathy, negative attitudes toward women, rape or sexual harassment myth acceptance, and self-reported acceptance of or 
likelihood of perpetrating the behavior. Prevention programs may be successful at changing some of these intermediate outcomes in the desired direction, although the ability of prevention programs to actually prevent the behavior itself is inconclusive (Brecklin \& Forde, 2001).

\section{Evaluation of Prevention Interventions}

Many prevention programs appear to be effective at teaching people what constitutes harassment and assault, increasing empathy for victims, decreasing rapesupportive attitudes (e.g. rape or harassment myth acceptance), and decreasing men’s reported likelihood of committing these behaviors (Brecklin \& Forde, 2001; O'Donohue et al., 1998; O'Donohue, Yeater, \& Fanetti, 2003). However, certain individual factors (e.g., potential for sexual coercion) and certain program conditions (e.g., gender of facilitator) are important to consider when developing interventions (Brecklin \& Forde, 2001; Stephens \& George, 2004; Winkel \& de Kleuver, 1997). The O’Donohue et al. (2003) study demonstrated that men with a history of coercive behavior responded more positively to the video-based program than men without a history of coercive behavior. Alternatively, Stephens \& George (2004) investigated the effectiveness of a video-based anti-rape program about acquaintance rape with 45 (primarily white) undergraduate men and demonstrated that for noncoercive men, there was a decrease in rape myth acceptance after watching the video-based prevention program, while there was no such decrease for coercive men.

Beyond individual characteristics of participants in intervention programs, the content of programs needs to be taken into consideration. A study by Winkel \& Kleuver (1997) indicates that anti-rape efforts may inadvertently increase rape-supportive 
attitudes. In their study, Sixty-two young Dutch men viewed a video-based program that was either perpetrator-focused or victim-focused. The perpetrator-focused film focused on the negative consequences of sexual harassment and sexual assault on the perpetrator (e.g., arrest), whereas the victim-focused film focused on the negative consequences for the victim. Men who participated in the perpetrator-focused program demonstrated an increase in their positive evaluation of macho behavior, rape myth acceptance and acceptance of coerced sex, whereas men who viewed the victim-focused film did not show these increases, but rather showed small decreases. Experienced prevention program developers also suggest that single-gender programs are essential since the construction and experience of masculinity increases men’s appreciation for antiharassment and anti-rape messages coming from other men (Berkowitz, 2002). In fact, the Brecklin \& Forde (2001) meta-analysis described above found that single-gender groups had more impact on male participants than did mixed-gender groups.

War Zone and the Prevention of Street Harassment

The film used in this study, War Zone, is a documentary that depicts the experience of street harassment as it occurs in various cities throughout the United States. The filmmaker shows men making sexual comments or gestures toward her and other women as she walks about the streets of New Orleans, Chicago, and New York. She then interviews a number of these men about their behavior. The filmmaker also interviews a number of women about their experiences with, and their reactions to, street harassment. The film highlights the often distressing impact that street harassment has on women, with particular emphasis placed on the relationship between street harassment and women's fear of rape. Her video has been influential to women's organizations (The 
Street Harassment Project, 2005) and is used to teach and talk about street harassment (CampusActivism, 2002).

The research on sexual harassment and sexual assault prevention programs has implications for the utility of War Zone as an intervention. Prevention programs that focus less on psychoeducation and more on the impact of the behavior appear to do better than programs that rely heavily on psychoeducation (Stephens \& George, 2004). The filmmaker spends only a small portion of time educating viewers directly about the nature of street harassment, but rather allows the behaviors, perpetrators, and victims to speak for themselves in an effort to demonstrate the often harmful, frightening and hostile nature of the behavior.

Second, the film may debunk myths about street harassment. In the sexual assault literature, rape myths are often associated with perpetration and rape-supportive attitudes (Lonsway \& Fitzgerald, 1994) and are often a target of sexual assault prevention (O’Donohue et al., 2003). The film demonstrates that street harassment happens to many different types of women, is perpetrated by a variety of men, and often has a negative impact on women. These depictions may help debunk myths about the type of women who experience street harassment (e.g., only women dressed sexily) and the people who perpetrate it (e.g., only men of lower socioeconomic groups).

Third, viewing street harassment behaviors as they actually happen and the resulting reactions of both the perpetrators and victims may help increase men's empathy for women who experience street harassment and reduce men's acceptance of the behavior. Developing specific empathy for victims has been a target of sexual victimization prevention programs and may develop best when men are able to relate to 
victim’s experiences (i.e., male victims; Brecklin \& Forde, 2001). One drawback to this video may be that it does not depict men's reactions to street harassment coming from other people (men or women) which may have contributed to increasing men's empathy for women.

Fourth, video-based formats are common in prevention programs and appear to be useful in educating viewers and changing important attitudes that may be related to sexual victimization perpetration (Stephens \& George, 2004). War Zone is a unique documentary film that is intended to capture the attention of viewers with a mix of creative cinematography, interviews, and evocative depictions of street harassment.

Although the film has potential strengths as an intervention, it may also have a few weaknesses. Specifically, research indicates that men respond better to programs facilitated by men in a non-confrontational manner (Berkowitz, 2002). However, the film itself is made and narrated by a woman who frequently confronts men about their behavior, which could negatively impact men’s receptivity to the film’s message. Importantly, this film is being evaluated for its potential as a component of a street harassment prevention program and will not be accompanied by other components, such as a male-facilitated discussion on the issue which could be included in a comprehensive program.

Last, even if the film contains many components that could contribute to its utility, the evaluation research indicates that certain types of men (e.g. "high risk”) may not be receptive to the film. Drawing from the sexual victimization literature, hostility toward women is expected to be related to empathy and may inhibit any effect the film would otherwise have on men's empathy. It is also possible that men with hostile 
attitudes may react negatively to the film because of the filmmaker's confrontation of men's behavior, which may be viewed as challenging traditional power dynamics. Peer acceptance of the behavior is also possibly related to the intermediate outcome of acceptance since the victimization literature tells us that men's peer groups can often have a strong impact on their views and behaviors. Attitudes and behaviors that are more entrenched and normalized within a peer group may be less susceptible to change. Preliminary Investigation of War Zone

Prior to this study, I conducted two focus groups with undergraduate men to examine men's receptivity to the film. The men first viewed the film and were asked a series of questions designed to get a general sense of men's reactions to the film. Although men had a variety of reactions to the film, including some who did and did not like it, many of the men thought the film could be useful in changing men's perceptions of street harassment, particularly for some specific groups of men (e.g., men who perpetrate street harassment). Some men in the groups made hostile comments about the film and the filmmaker (e.g. did not trust the filmmaker and thought that she had staged all the instances of street harassment) and were not in favor of using the film in future prevention efforts. The varying reactions suggested the importance of further investigating the usefulness of the film and confirmed concerns implicated in sexual harassment and sexual assault research that suggests that the film may not have universal benefits. 
The Present Study

Logic Model for the Intervention

As a consequence of the theoretical link between sexual assault, harassment, and street harassment, expectations about War Zone's ability to prevent street harassment are drawn from what is known about effective sexual assault and harassment prevention efforts. The main way in which this film is expected to be useful in preventing street harassment is through increasing men's cognitive and affective empathy for women who experience street harassment, thereby decreasing their acceptance of the behavior (see Figure 1).

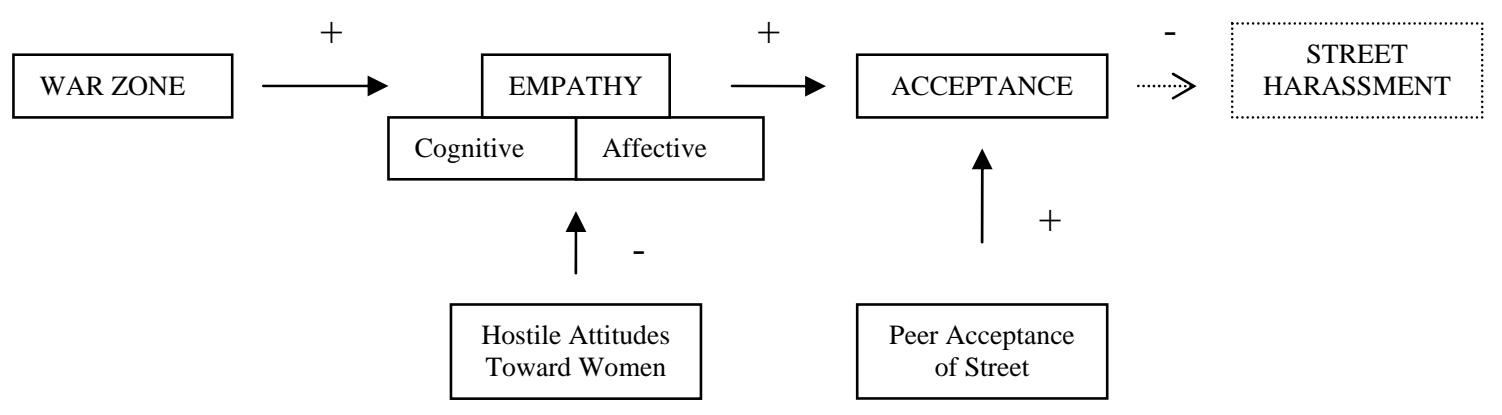

Figure 1: Logic Model for War Zone's Impact on Attitudes Toward Street Harassment Hypothesized direction of the relationship is indicated by + or - sign.

Specifically, the film shows the negative reaction many women have to street harassment, which should increase men's ability to take the woman's perspective, thereby increasing men's cognitive empathy. The film may affect affective empathy by 
depicting some of the disturbing street harassment behaviors and the negative and often frightening consequences for women. Men may have a vicarious emotional experience in which they become both distressed and more sympathetic after witnessing the suffering of the women who experience the behavior in the film. Theoretically, such an increase in cognitive and affective empathy should impact men’s perception of street harassment such that they would perceive street harassment as problematic and less acceptable. The intervention is expected to increase empathy first, and decrease acceptance second.

Previous research indicates that attitudes and affect men have toward women and the influence of their peer groups are related to the intermediate outcomes of empathy and acceptance. Men who are more hostile toward women and more sexist (particularly hostile sexism) are expected to be less empathic toward victims of street harassment and therefore more accepting of the behavior. Further, those whose peer groups are more accepting of the behavior are expected to be influenced by their milieu, and so should also be more accepting of the behavior.

\section{Hypotheses}

I developed one research question and two major hypotheses in an effort to assess the utility of the film War Zone as a component of a street harassment prevention intervention.

\section{Question 1:}

What are men's opinions of the film? This research question is intended to ascertain men's opinions of War Zone and whether they appreciate various aspects of the film. Theoretically, if men do not have much appreciation for the film's content and style, the film may be less useful and effective. It is important to note that the viewer may 
actually dislike parts or aspects of the film, and yet appreciate those same parts or aspects as important contributions to the overall purpose of the film.

Hypothesis 1:

War Zone will cause an increase in cognitive and affective empathy. The film is expected to increase both men's cognitive and affective empathy for victims. Therefore, I hypothesized that men who view War Zone will have higher levels of both cognitive and affective empathy than men who view the comparison film.

Hostility Toward Women will moderate the relationship between film condition and empathy. Men who are more hostile toward women may be less open to understanding and empathizing with the women's negative experiences with street harassment that are portrayed in the film. In fact, these men may be angered by the confrontational approach of the filmmaker. Therefore, I hypothesized that hostility toward women will moderate the relationship between film condition and both cognitive and affective empathy such that an increase in hostility will be related to a decrease in empathy.

Sexist beliefs will moderate the relationship between film condition and empathy. Men who hold sexist beliefs about women, specifically hostile sexist beliefs, may be less open to understanding and empathizing with the women’s negative experiences with street harassment that are portrayed in the film. In fact, similar to the relationship between hostility toward women and empathy, men who report hostile sexist beliefs may in fact be angered by the confrontational approach of the filmmaker. Therefore, I hypothesized that hostile sexism will moderate the relationship between film condition 
and cognitive and affective empathy such that an increase in hostile sexism will be related to a decrease in empathy.

Hypothesis 2:

War Zone will decrease acceptance of street harassment. The film is expected to increase men's empathy for women who experience street harassment and, therefore, decrease men's acceptance of the behavior. I hypothesized that men who view War Zone will report less acceptance of street harassment than men who view the control film.

Empathy will moderate the relationship between film condition and acceptance of street harassment. Acceptance of street harassment is expected to be lower in the group who viewed War Zone, but only for those men who report higher empathy. Therefore, I hypothesized that empathy will moderate the relationship between film condition and acceptance, with more empathy being related to less acceptance of street harassment.

Peer acceptance of street harassment will moderate the relationship between film condition and acceptance of street harassment. Peer groups appear to have a significant impact on men's acceptance of sexual victimization. If men belong to a peer group that is highly accepting of the behavior, the film may not be as effective in reducing their acceptance to street harassment. Therefore, I hypothesized that peer acceptance of street harassment will moderate the relationship between film condition and acceptance of street harassment, such that higher peer acceptance of street harassment will be related to higher acceptance of street harassment. 


\section{METHOD}

Design

This study used an experimental independent groups design with one intervention group and one comparison group in which all participants were assessed after viewing the film to which they were assigned (War Zone or Under Antarctica Ice). This is the best design to determine if differences between empathy and acceptance for the two groups are due to the intervention, and to test the various moderation hypotheses. The survey given to participants was counter-balanced to balance order effects. Specifically, six of the seven measures were paired together in a consistent order, and then each pair and the single measure were placed in 24 different orders, with the demographics section always last. Men were then randomly assigned a survey order.

\section{Participants}

Participants for this study were 82 male undergraduate psychology students at Georgia State University (GSU) enrolled in an introduction to psychology course who received class credit for their participation. The GSU undergraduate student body is comprised of 28\% African-American, 49\% Caucasian, 3\% Hispanic, 11\% Asian or Pacific Islander, and $<1 \%$ Native American students (Board of Regents of the University System of Georgia, 2004). The study sample somewhat reflects these racial/ethnic demographics. Caucasians comprised $60 \%$ of the sample, followed by African-American (18\%), East Asian (7\%), South Asian (5\%), Multiracial (5\%), Other (2\%) and Latino/a (1\%). The men in this sample were of traditional college age $(M=20.88, S D=3.55)$ and tended to be in their 1 st (35\%) and $2^{\text {nd }}$ (33\%) years of study. Twelve percent were in their $3^{\text {rd }}$ year and $16 \%$ in their $4^{\text {th }}$ year. Most men reported they were dating someone, either in 
a non-committed relationship (24\%) or a committed relationship (37\%). Thirty-eight percent of the men were single. The majority of men reported their sexual orientation as heterosexual (66\%), followed by homosexual (9\%), other (2\%), and bisexual (1\%).

Experimental Conditions

War Zone

As previously described, the film of interest, War Zone, is a documentary that depicts and interviews men and women about the experience of street harassment as it occurs in various cities throughout the United States.

\section{Comparison Film}

The alternative film to be used in this study will be Under Antarctica Ice. This film captures many landscapes and ocean life inhabiting the sea beneath the ice of Antarctica. It was chosen because, although expected to be interesting, is not expected to induce any particular emotion from participants, and is a film focused on land and sea as opposed to humans or human behavior.

\section{Measures}

\section{Appreciation for the Film}

Participants’ opinions were documented by assessing their overall appreciation for the film. To clarify what participants were referring to in their answers to the appreciation of film measure, I asked participants to describe what the film is about. Appreciation was assessed by asking participants to consider whether various aspects of the film contribute to the overall utility of the film in changing men's attitudes about street harassment (see Appendix). For participants who viewed the alternative film, they 
were asked whether they think the film is useful in teaching about life in the ocean under Antarctica ice.

Participants rated whether the film's content is valuable (useful and important), whether the film's cinematography and filmmaker's approach are effective (help get the film's message across), and whether the film is useful in teaching about street harassment/life under Antarctica ice, on a scale from 1 (is not) to 5 (extremely). The average of the 4 scores indicates the participants' appreciation for the film. Theoretically, if men appreciate the film overall, they are likely to appreciate most or all aspects of the film identified in the measure, however, it may be that men appreciate only certain aspects of the film. The reliability of the measure for the present study was $\alpha=.75$ ( $n=$ 40; War Zone condition), and for men in the comparison condition, $\alpha=.73(n=42)$.

\section{Hostility Toward Women}

Hostility toward women was measured using Lonsway \& Fitzgerald’s (1995) adapted version of the Hostility Toward Women Scale (Check, Malamuth, Elias, \& Barton, 1985). This scale is frequently used and is the most recent and succinct version of a scale measuring hostility toward women. The adapted scale contains 10 items for which participants agree (1) or disagree (7) on a 7 point Likert scale. Reliability for the scale was examined using 200 (100 male and 100 female) undergraduate students in psychology with an average age of 18.6 years (race/ethnicity unreported). The scale demonstrated associations with rape myth acceptance and related rape-supportive attitudes, suggesting it adequately measures the intended construct. Further, Cronbach’s alpha for this sample was .83 (Lonsway \& Fitzgerald, 1995). The reliability of the scale 
in the present study was $\alpha=.85$ ( $n=40$; War Zone condition), and for men in the comparison condition, $\alpha=.86(n=42)$.

\section{Sexism}

Sexism was measured using the Ambivalent Sexism Inventory (Glick \& Fiske, 1996). The ASI is the predominant measure of both hostile sexism and benevolent sexism. This hostile sexism subscale includes 12 items reflecting negative and prejudicial attitudes toward women with which participants indicate how much they agree or disagree $(0$ = disagree strongly and 5 = agree strongly). The benevolent sexism subscale includes 10 items measured on the same scale that reflect attitudes that, although they are subjectively positive, place women in stereotypical and restricted roles that tend to support men’s dominance over women.

Data examining reliability and validity was obtained from six samples, four of which were undergraduate students, and one of which included men and women from public places around town (e.g. malls, restaurants, laundromats). Expected relationships with key constructs such as other sexism scales, stereotypes about women, and hostility toward women support the validity of the ASI. Reliability coefficients for all samples ranged from .80 to .92 for the Hostile Sexism subscale and from .73 to .85 for the Benevolent Sexism subscale (Glick \& Fiske, 1996).

For men in the War Zone condition, $\alpha=.83(n=40)$ for the hostile sexism subscale and $\alpha=.76$ for the benevolent sexism subscale. For men in the comparison condition, $\alpha=.88(n=42)$ for the hostile sexism subscale and $\alpha=.83$ for the benevolent sexism subscale. 


\section{Empathy}

I assessed two different aspects of empathy for women who experience street harassment, including; the cognitive ability to take the perspective of another person, and affective responses to witnessing the suffering of another person. The perspective-taking ability was assessed by adapting the Rapist Empathy Measure (REM; Fernandez \& Marshall, 2003). Few measures of cognitive empathy exist for victims of sexual assault, and those that do tend to be either geared toward the specific circumstances of sexual assault, or created for use in one specific study; however, the REM is easily adapted to measure empathy for a woman experiencing street harassment.

The REM consists of vignettes, one of which briefly describes the rape of an unknown woman. After reading the vignette, men are asked to rate on a scale from 0 (not at all) to 10 (very much) how much the woman who had been assaulted was feeling 30 different feelings (e.g., sad, angry, fearful of being hurt, relaxed, proud of self). Ratings for 25 of the 30 feelings the woman felt are positively keyed and 5 are negatively keyed. Negatively keyed items are subtracted from 10 and then summed with the positively keyed items to get a score out of 300 for this subscale. Reliability of the REM in a small sample of undergraduate males (race/ethnicity unreported) enrolled in an introductory psychology course was .90. Two weeks later, test-retest reliability was $r=.84$ (Fernandez \& Marshall, 2003).

The adapted measure includes 10 feelings that research suggests are indicated in street harassment. The brief vignette reads: A woman is walking down the street when she hears a man that she does not know whistle at her and say "nice ass". The 10 feelings include: complimented, offended, proud, ashamed, self-confident, guilty, pleased, afraid, 
angry, and safe. Participants will choose, on a scale from 1 (not at all) to 10 (very much), how much the woman who has been street harassed is feeling each of the 10 feelings. The negatively-keyed items (complimented, proud, self-confident, pleased, and safe) were subtracted from 10 and then added to the positively-keyed items to obtain a score out of 100. Higher scores represent more empathy, or the perception that the experience is negative for women. For men in the War Zone condition, $\alpha=.79(n=40)$, and for men in the comparison condition, $\alpha=.83(n=42)$.

The affective component of empathy was measured using the Emotional Response Questionnaire (ERQ; Baston et al., 1983). The ERQ measures two distinct affective reactions to witnessing another person's suffering; distress (alarmed, grieved, upset, worried, disturbed, perturbed, distressed, troubled) and empathy (sympathetic, moved, compassionate, tender, warm, softhearted). The items in both subscales are rated by the participant on a scale from 1 (not at all) to 7 (extremely). To compute the scales, items are summed together and divided by the number of items. Baston et al. (1983) examined the structure of the ERQ using factor analysis and found that for 88 female and male undergraduate students (race/ethnicity unreported), the 14 items loaded onto the expected subscale. Further, they found that type of emotional response (personal distress versus empathy) was related to participants’ behavior (egoistic or altruistic) in the expected direction. Reliability coefficients for three separate groups of participants ranged from .86 to .94 for the Personal Distress subscale and .79 to .90 for the Empathy subscale (Baston et al., 1983).

The Empathy subscale is considered equivalent to sympathy by the authors and so will be called sympathy for clarity in my study. Further, although the authors suggest that 
sympathy and personal distress are distinct vicarious emotional responses to witnessing the suffering of another person, I refer to both the Personal Distress subscale and the Empathy subscale as types of affective empathy for ease of discussion and since both are vicarious emotional responses. Each measure was assessed separately and both were expected to increase as a consequence of viewing War Zone. For this study, participants read the same brief vignette provided in the adapted REM and asked how much they feel the 14 ERQ items.

For the distress subscale men in the War Zone condition, $\alpha=.91(n=40)$, and for men in the comparison condition, $\alpha=.94(n=42)$. For the sympathy subscale men in the War Zone condition, $\alpha=.85(n=40)$, and for men in the comparison condition, $\alpha=.84$ $(n=42)$.

\section{Acceptance of Street Harassment}

A scale measuring men’s acceptance of street harassment was created specifically for this study using the method employed by Goodchilds and Zellman (1984) to assess acceptance of sexual aggression. In their work, participants were asked under what circumstances sexual aggression is justified. This study assessed under what circumstances participants think street harassment is acceptable. Participants were asked to indicate on a scale from 1 (not at all acceptable) to 5 (very acceptable), whether they think it is acceptable for a man to engage in unsolicited and unreciprocated behavior on the street to an unknown woman under 11 different circumstances (e.g., "when she is attractive”, "when she is wearing a short skirt”, etc.). The participant rated the acceptability of behavior for both comments (e.g., "hey baby or “nice ass”) and touching (e.g., grabbing a woman’s buttocks or brushing up purposely against a woman) 
separately. These circumstances were chosen based on qualitative information from previous research studies and information gained from the previously conducted focus groups regarding myths about what types of women typically experience street harassment, under what type of circumstances, and by what type of men. The sum of the participant's scores for each of the 11 conditions reflects their level of acceptance of street harassment. Scores were computed separately for making comments and touching.

For making comments, in the War Zone condition, $\alpha=.92(n=40)$ and $\alpha=.93(n$ $=42$ ) in the comparison condition. For touching, in the War Zone condition, there was no variance between items as all participants rated touching as not acceptable. For the comparison condition $\alpha=.86$.

\section{Peer Acceptance of Street Harassment}

Peer acceptance of street harassment was measured using the same method used to assess the participant's acceptance of street harassment. The question was modified to ask men under what circumstances they think their male friends think it is okay for a man to engage in unsolicited and unreciprocated behavior (comments and touching) in public toward an unknown woman on the street.

For making comments, in the War Zone condition, $\alpha=.95(n=40)$ and $\alpha=.94(n$ $=42$ ) in the comparison condition. For touching, in the War Zone condition $\alpha=.98$ and $\alpha$ $=.92$ for the comparison condition.

\section{Procedure}

Men were solicited via an internet web site officially affiliated with the Georgia State University Department of Psychology that is used to schedule participation in university research studies. The website contains information about all the research 
studies available at a given point in the semester and men are able to select which study to participate in from among those offered. Men who participated in this study signed up for a specific appointment time and met with the researcher or research assistant at a location on the university campus within the Psychology Department. Data were collected in groups of ten or less. To control gender of experimenter as a potential confound, groups were randomly assigned to either a man or a woman researcher. Each group of men was randomly assigned to either view the War Zone or the comparison film Under Antarctic Ice, so that in the end, about half of the men saw War Zone $(n=40)$ and about half of the men saw the comparison film $(n=42)$.

Participants reviewed their rights as a participant, the confidentiality of their participation and anonymity of responses to the questions, and consented to participation with the researcher or research assistant. At the beginning of the study and in the consent form, participants were told that the purpose of the study was to “...compare men’s reactions to two documentary films and determine if various social attitudes may or may not be related to the films”. Participants then viewed the film to which they had been randomly assigned, after being reminded that they could withdraw their participation if they become uncomfortable, without penalty. After watching the film, participants completed the counterbalanced measures. Subsequent to participation, participants were given a debriefing sheet and told that the purpose of the study was to “...investigate men's reactions to the film that is entitled War Zone to see if the film may be useful in impacting men’s attitudes toward a behavior called street harassment.” They were also given contact information for resources on street harassment and referrals for 
psychological services in the event that they felt any psychological discomfort. The study took less than two hours to complete.

\section{Planned Statistical Analyses}

The sample size was set at 80 participants so that I could achieve sufficient statistical power (.83), assuming a small effect size $\left(r^{2}=.10\right)$. For all analyses, the significance level was set to $\mathrm{p}<.05$.

Data from the study was entered into a database and checked for accuracy by the researcher. The data was cleaned and each variable was examined to assess the distribution, identify outliers and identify possible errors. Descriptive statistics were also calculated for each variable.

Men’s appreciation for the film was assessed by examining the frequency with which men's average rating of the usefulness of the film fell into one of the five categories spanning "is not” to "extremely".

Relationships between film condition, cognitive and affective empathy, hostility toward women and sexism were examined using correlational-multiple regression system (Cohen \& Cohen, 1983; see Table A1 in the Appendix). To determine whether film condition is related to empathy, and whether hostility toward women and hostile sexism individually moderate the relationship between film condition and empathy, hierarchical regression analysis was used (Baron \& Kenny, 1986). Similar analyses were conducted to investigate the relationships between film condition, acceptance of street harassment, empathy and peer acceptance of street harassment. 


\section{RESULTS}

Each variable in the analyses was evaluated for missing data, outliers (SD > 3), and deviations from normality (see Table 1). There was very little missing data with no apparent pattern; therefore, missing data points for each item with missing data were replaced with the mean of that item for the appropriate film condition (Allison, 2001).

Table 1: Means and Standard Deviations for War Zone $(n=40)$ and Under Antarctica Ice $(n=42)$, and Variable Correlations with Film Condition $(N=82)$.

\begin{tabular}{|c|c|c|c|c|c|c|}
\hline & & & \multicolumn{2}{|c|}{ War Zone } & \multicolumn{2}{|c|}{ Under Antarctica } \\
\hline Variable & $\begin{array}{l}\text { Correlation } \\
\text { with Film } \\
\text { Condition }^{\mathrm{a}}\end{array}$ & $\begin{array}{l}\text { Scale } \\
\text { Range }\end{array}$ & Mean & $\begin{array}{c}\text { Standard } \\
\text { Deviation }\end{array}$ & Mean & $\begin{array}{c}\text { Standard } \\
\text { Deviation }\end{array}$ \\
\hline $\begin{array}{l}\text { Appreciation } \\
\text { for the film }\end{array}$ & $.22 *$ & $1-5$ & 3.10 & .98 & 3.48 & .72 \\
\hline $\begin{array}{l}\text { Hostility } \\
\text { toward } \\
\text { women }\end{array}$ & .13 & $1-7$ & 3.06 & .95 & 3.33 & 1.12 \\
\hline Hostile sexism & -.03 & $0-5$ & 2.49 & .90 & 2.44 & .92 \\
\hline $\begin{array}{l}\text { Benevolent } \\
\text { sexism }\end{array}$ & -.17 & $0-5$ & 2.80 & .85 & 2.50 & .92 \\
\hline $\begin{array}{l}\text { Cognitive } \\
\text { empathy }\end{array}$ & -.12 & $0-100$ & 60.01 & 13.78 & 56.55 & 15.62 \\
\hline Distress & -.06 & $1-56$ & 26.99 & 11.37 & 22.65 & 12.53 \\
\hline Sympathy & -.01 & $1-42$ & 15.40 & 6.73 & 15.33 & 6.88 \\
\hline Acceptance $^{\mathrm{b}}$ & $-.11^{\mathrm{a}}$ & $1-55$ & 20.30 & 7.87 & 18.86 & 8.18 \\
\hline $\begin{array}{l}\text { Peer } \\
\text { acceptance }^{\mathrm{b}}\end{array}$ & $-.20^{\mathrm{a}}$ & $1-55$ & 26.50 & 10.59 & 22.55 & 9.55 \\
\hline
\end{tabular}

Note: $* p<.05$; ${ }^{\mathrm{a}}$ War Zone $=0$, Comparison film $=1 ;{ }^{b}$ natural log of variable 
Only two variables, acceptance and peer acceptance of street harassment, were significantly skewed. Their positive skew reflects that most participants scored low on the acceptance and peer acceptance measures. These scores were transformed by computing the natural log of the variable for use in the analyses.

The acceptance variable did contain one outlier; however, after examination of the outlier and the effect the data point had on the analyses after transforming the variable, I decided to not omit the participant's data. Although men were asked about acceptance and peer acceptance of touching women on the street, men generally reported that touching was "not at all acceptable”. Therefore, data for touching acceptance and touching peer acceptance were not included in the analyses.

\section{Question 1 \\ Men's Opinions of the Film}

Overall, men's reported appreciation of the film was just above "somewhat” (see Table 2).

Table 2: Appreciation for the Film

\begin{tabular}{|c|c|c|c|c|c|c|c|c|c|c|}
\hline \multirow{2}{*}{$\begin{array}{l}\text { Film } \\
\text { condition }\end{array}$} & \multicolumn{2}{|c|}{$\begin{array}{l}\text { The film's } \\
\text { content is } \\
\text { valuable }\end{array}$} & \multicolumn{2}{|c|}{$\begin{array}{c}\text { Cinematogra } \\
\text { phy is } \\
\text { effective }\end{array}$} & \multicolumn{2}{|c|}{$\begin{array}{c}\text { Filmmakers' } \\
\text { approach is } \\
\text { effective }\end{array}$} & \multicolumn{2}{|c|}{$\begin{array}{l}\text { The film } \\
\text { useful for the } \\
\text { topic }\end{array}$} & \multicolumn{2}{|c|}{$\begin{array}{c}\text { Overall } \\
\text { appreciation } \\
\text { of the film }\end{array}$} \\
\hline & $M$ & $S D$ & $M$ & $S D$ & $M$ & $S D$ & $M$ & $S D$ & $M$ & $S D$ \\
\hline War Zone & 3.48 & 1.09 & 2.98 & 1.31 & 3.15 & 1.27 & 2.80 & 1.45 & 3.10 & .98 \\
\hline $\begin{array}{l}\text { Under } \\
\text { Antarctica Ice }\end{array}$ & 3.10 & .91 & 3.65 & 1.03 & 3.27 & .91 & 3.91 & 1.05 & 3.48 & .72 \\
\hline
\end{tabular}


Men's variation within the four appreciation of the film questions is best seen in the graphs in Figure 2.

The film's content is valuable

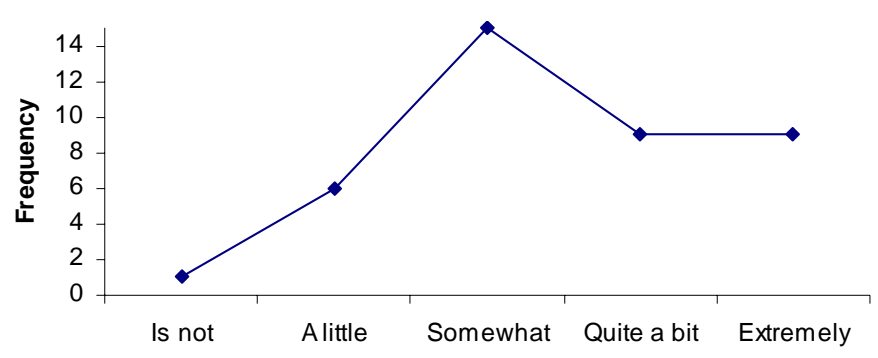

Cinematography is effective

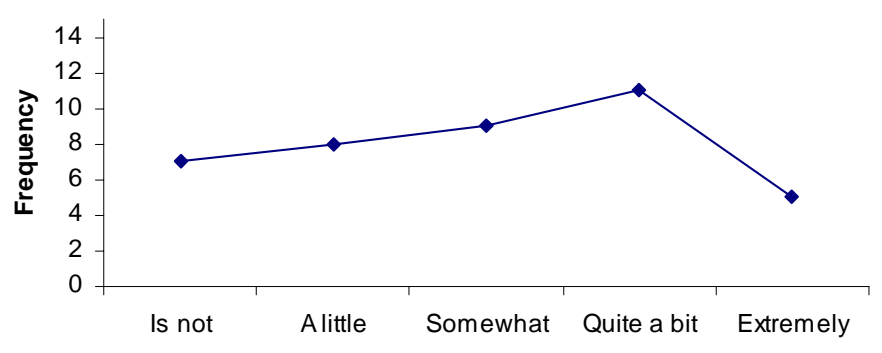

Filmmakers' approach is effective

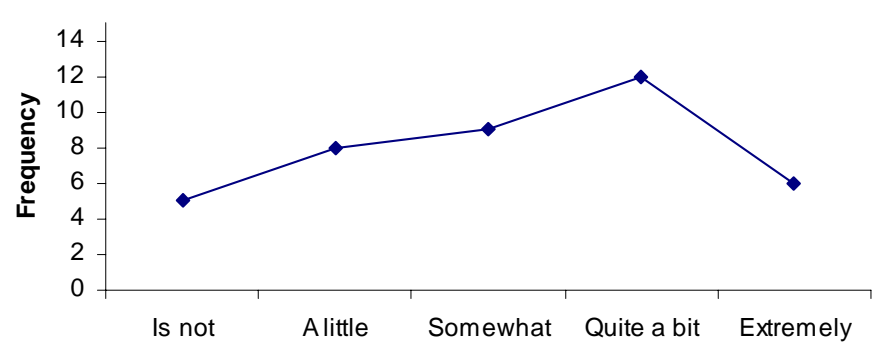

Figure 2: Category Frequency for Appreciation for the Film War Zone $(n=40)$ 
The film is useful for the topic

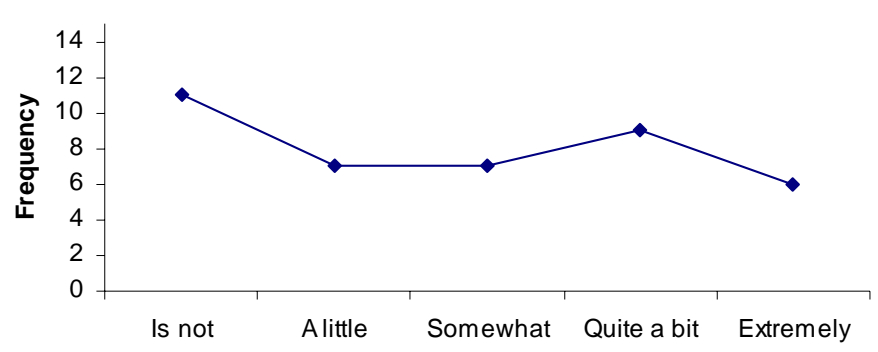

Figure 2 continued: Category Frequency for Appreciation for the Film War Zone ( $n=$ 40)

\section{Hypothesis 1}

Film Condition Will Predict Cognitive and Affective Empathy, and Will Be Moderated by

\section{Hostile Attitudes Toward Women}

Regardless of how empathy was measured, film condition was not related to empathy (see Table 3). Neither hostility toward women nor hostile sexism moderated the relationship between film condition and cognitive empathy, distress, or sympathy.

Hypothesis 2

Film Condition Will Predict Acceptance of Street Harassment, and Will Be Moderated by Empathy and Peer Acceptance of Street Harassment

The data did not support that film condition was related to acceptance of street harassment (see Table 4). Cognitive empathy, distress, and sympathy did not moderate the relationship between film condition and acceptance of street harassment. Peer acceptance also did not moderate the relationship between film condition and acceptance of street harassment. 
Table 3: Summary of Hierarchical Regression Analyses Predicting Forms of Empathy (N $=82)$

$\beta \quad \Delta$ in $R^{2} \quad$ Adjusted $R^{2}$

Cognitive empathy

Film condition

$-.10 \quad .01$

Hostility toward women

$-.25 \quad .02$

Film condition X hostility toward women

$.13 \quad .01$

.01

Distress

Film condition

Hostility toward women

$\begin{array}{ll}-.03 & .00\end{array}$

$-.36 * \quad .03$

Film condition X hostility toward women

.24

.02

.02

Sympathy

Film condition

$.00 \quad .00$

Hostility toward women

$-.07$

.00

Film condition X hostility toward women

.05

.00

$-.04$

Cognitive Empathy

Film condition

$\begin{array}{ll}-.13 & .01\end{array}$

Hostile sexism

$-.33^{*}$

$.05^{*}$

Film condition $\mathrm{X}$ hostile sexism

.14

.01

.04

Distress

Film condition

$\begin{array}{ll}-.06 & .00\end{array}$

Hostile sexism

$\begin{array}{ll}-.25 & .03\end{array}$

Film condition $\mathrm{X}$ hostile sexism

.11

.01

.00

Sympathy

Film condition

$\begin{array}{ll}-.01 & .00\end{array}$

Hostile sexism

$-.08$

.00

Film condition $\mathrm{X}$ hostile sexism

.09

.00

$-.03$

Note: $\beta$ s and Adjusted $R^{2}$ are from the final model; ${ }^{*} p<.05$ 
Table 4: Summary of Hierarchical Regression Analyses Predicting Acceptance of Street Harassment $(N=82)$

$\beta \quad \Delta$ in $R^{2} \quad$ Adjusted $R^{2}$

Acceptance of street harassment

Film condition

Cognitive empathy

Film condition X cognitive empathy

Acceptance of street harassment

Film condition

Distress

Film condition $\mathrm{X}$ distress

Acceptance of street harassment

Film condition

Sympathy

Film condition X Sympathy

Acceptance of street harassment

Film condition

Peer acceptance

Film condition X Peer acceptance
$-.17 \quad .01$

$-.60 * \quad .17 *$

$.23 \quad .02$

$\begin{array}{ll}-.13 & .01 \\ -.26 & .03\end{array}$

$-.26$

$.12 \quad .01$

$\begin{array}{ll}-.12 & .01\end{array}$

$\begin{array}{ll}-.15 & .01\end{array}$

$.08 \quad .00$

$\begin{array}{ll}-.05 & .01\end{array}$

$.69 * \quad .47 *$

$.07 \quad .00$
.01

$-.01$

$.18^{*}$

$.46 *$

Note: $\beta$ s and Adjusted $R^{2}$ are from the final model; ${ }^{*} p<.05$; $\mathrm{DV}=$ natural $\log$ of acceptance variable

\section{Supplementary Analyses}

In this study I manipulated the gender of the researcher such that half of the men in each group participated in the experiment with same woman and half with the same man. This variable could have caused variability in the intermediate outcomes of empathy and acceptance which could have decreased the observed effect of film condition on empathy and acceptance. To examine this possibility, I reanalyzed the relationships between film condition and empathy and film condition and acceptance while controlling for the effect of gender of the researcher. None of the regression analyses resulted in a significant effect of film condition on empathy or acceptance (see Table 5). 
Similarly, although men were given random orders of the measures, the counterbalance condition could have caused variability within the intermediate outcomes of empathy and acceptance. To examine whether the effect of film condition increases when controlling for the effect of counterbalance condition, I categorized the counterbalance orders into four categories (each set of measures placed first) and dummy coded the variable. None of the regression analyses resulted in a significant effect of film condition on empathy or acceptance (see Table 5).

$$
\text { Exploratory Analyses }
$$

Although the data did not support my hypotheses, numerous interesting and potentially informative relationships and patterns in the data emerged that warranted further exploration.

\section{Predictors of Acceptance of Street Harassment}

\section{Empathy}

According to the hierarchical regression analyses conducted, cognitive empathy was positively related with acceptance across groups.

Peer Acceptance of Street Harassment

According to the hierarchical regression analyses conducted, it appears that peer acceptance is positively related with acceptance across groups. Although not hypothesized, men reported that their peers were more accepting of street harassment than they were themselves under all conditions (see Table 6). 
Table 5: Summary of Hierarchical Regression Analyses Predicting Forms of Empathy and Acceptance $(N=82)$

$\beta \quad \Delta$ in $R^{2} \quad$ Adjusted $R^{2}$

Cognitive empathy

Gender of researcher

$\begin{array}{ll}.13 & .02\end{array}$

Film condition

$-.12$

.01

.01

Distress

Gender of researcher

$\begin{array}{ll}-.01 & .00\end{array}$

Film condition

$\begin{array}{ll}-.06 \quad .00 & .00\end{array}$

$-.02$

Sympathy

Gender of researcher

$.10 \quad .01$

Film condition

$-.01$

.00

$-.01$

Acceptance $^{\mathrm{a}}$

Gender of researcher

$.04 \quad .00$

Film condition

$-.11$

.01

$-.01$

Cognitive empathy

Counterbalance condition

.03

Film condition

$-.12$

.01

$-.01$

Distress

Counterbalance condition

Film condition

$-.05$

.01

mpathy

Counterbalance condition

Film condition

.00

.01

.00

$-.04$

Acceptance $^{\mathrm{a}}$

Counterbalance condition

.03

Film condition

$-.11$

.01

$-.01$

Note: $\beta$ s and Adjusted $R^{2}$ are from the final model; ${ }^{a}$ natural log transformation;

Counterbalance condition variable is comprised of three dummy coded variables. 
Table 6: Percentage of Men Who Rated Acceptance and Peer Acceptance Items as Acceptable to Some Degree $(N=82)$

Acceptance Condition

When she is attractive

When she is dressed in sexy clothing

When she makes eye contact with him

When she smiles at him

When she is alone

When she is with her friends

When she is with a man

When she is with her children

When he is alone

When he is with his friends

When he is in an unfamiliar neighborhood
Acceptance \% $\quad$ Peer Acceptance \%

$\begin{array}{cc}53 & 74 \\ 67 & 77 \\ 72 & 82 \\ 76 & 85 \\ 33 & 60 \\ 55 & 66 \\ 16 & 27 \\ 5 & 15 \\ 40 & 54 \\ 35 & 62 \\ 26 & 35\end{array}$

To test whether men in either group reported higher levels of peer acceptance than their own acceptance, I conducted repeated-measures $t$-tests for both groups independently to assess the difference scores between peer acceptance and men's own acceptance. The means and standard deviations are displayed in Table 1. In the War Zone group, peer acceptance was higher than self acceptance, $t(39)=-5.10, p<.01, r^{2}=.4$. In the comparison group, peer acceptance was also higher than self acceptance, $t(41)=$ $-3.60, p<.01, r^{2}=.24$.

Hostility Toward Women

A review of correlation matrices among study variables suggests that the relationship between hostility toward women and acceptance of street harassment may be moderated by film condition (see Table 6). Specifically, the positive correlations between hostility toward women and acceptance of street harassment appeared to be different for each condition (i.e. stronger in the comparison condition $r=.24$ vs. .62). This relationship was examined using hierarchical regression as was done in the previous 
moderation analyses (refer to Table 8). Film condition did not moderate the relationship between hostility toward women and acceptance; however, the change in regression coefficient for the interaction approached significance at $p=.08$. Hostility toward women was related to acceptance across groups, such that men with high hostility scores also had high acceptance of street harassment.

Group Differences in the Relationship between Hostile and Benevolent Sexism Also notable in the correlation matrices presented in Table 7, is the relationship between hostile and benevolent sexism. The War Zone group had a smaller correlation

Table 7: Intercorrelations Between Variables

\begin{tabular}{|c|c|c|c|c|c|c|c|c|c|}
\hline Variable & 1 & 2 & 3 & 4 & 5 & 6 & 7 & 8 & 9 \\
\hline 1. Appreciation for the film & -- & -.30 & -.17 & $.42 *$ & .25 & $.55^{*}$ & .07 & -.11 & -.03 \\
\hline 2. Hostility toward women & .03 & -- & $.75^{*}$ & -.07 & -.25 & $-.35^{*}$ & -.06 & .24 & $.32 *$ \\
\hline 3. Hostile sexism & .25 & $.65 *$ & -- & .12 & $-.35^{*}$ & -.27 & -.08 & $.38 *$ & .28 \\
\hline 4. Benevolent sexism & .19 & $.32 *$ & $.64^{*}$ & -- & .04 & .16 & -.20 & .02 & -.01 \\
\hline 5. Cognitive empathy & .19 & -.08 & -.14 & -.06 & -- & $.42 *$ & .04 & $-.58^{*}$ & $-.53^{*}$ \\
\hline 6. Distress & .26 & -.04 & -.11 & -.12 & $.40^{*}$ & -- & $.43^{*}$ & -.26 & -.18 \\
\hline 7. Sympathy & .10 & -.01 & .04 & .13 & .18 & $.46^{*}$ & -- & -.16 & .04 \\
\hline 8. Acceptance ${ }^{\mathrm{a}}$ & .03 & $.62^{*}$ & $.59 *$ & .23 & -.29 & -.10 & -.04 & -- & $.70 *$ \\
\hline 9. Peer acceptance ${ }^{\mathrm{a}}$ & -.25 & $.48^{*}$ & $.37 *$ & 25 & $-.38^{*}$ & -.09 & -.22 & $.68^{*}$ & -- \\
\hline
\end{tabular}


Table 8: Summary of Exploratory Moderation Analyses $(N=82)$

\begin{tabular}{llll}
\hline & $\beta$ & $\Delta$ in $R^{2}$ & Adjusted $R^{2}$ \\
\hline & & & \\
Acceptance of street harassment & & & \\
$\quad$ Hostility toward women & .24 & $.19^{*}$ & \\
$\quad$ Film condition & -.17 & .03 & \\
$\quad$ Hostility toward women X film condition & $.27^{\mathrm{a}}$ & .03 & $.22^{*}$ \\
Benevolent sexism & & & \\
$\quad$ Hostile sexism & $.29^{*}$ & $.27^{*}$ & \\
$\quad$ Film condition & -.12 & .01 & \\
$\quad$ Hostile sexism X film condition & $.27^{\mathrm{b}}$ & $.03^{\mathrm{b}}$ & $.22^{*}$ \\
\hline
\end{tabular}

${ }^{*} p<.05 ;{ }^{\mathrm{a}} p=.08 ;{ }^{\mathrm{b}} p=.06 ;{ }^{\mathrm{c}} N=81$

between hostile and benevolent sexism, $r=.12, p=.47$, than the comparison group, $r=$ $.64, p<.01$. Examination of the scatter plot revealed that one participant's data in the War Zone group was notably different from the rest of the participants' data in that group.

The participant was particularly high on benevolent sexism and low on hostile sexism. When the participant's data was removed, the correlation of hostile and benevolent sexism was $r=.30, p=.06$, for the War Zone group. To test whether the relationship between hostile and benevolent sexism differs between groups, with the outlier data excluded in the analysis, a hierarchical regression was conducted (see Table 8). The results suggest that there is a trend toward the relationship between hostile and benevolent sexism being moderated by film condition, suggesting that the positive relationship is stronger in the comparison condition. This relationship is depicted in Figure 3. 


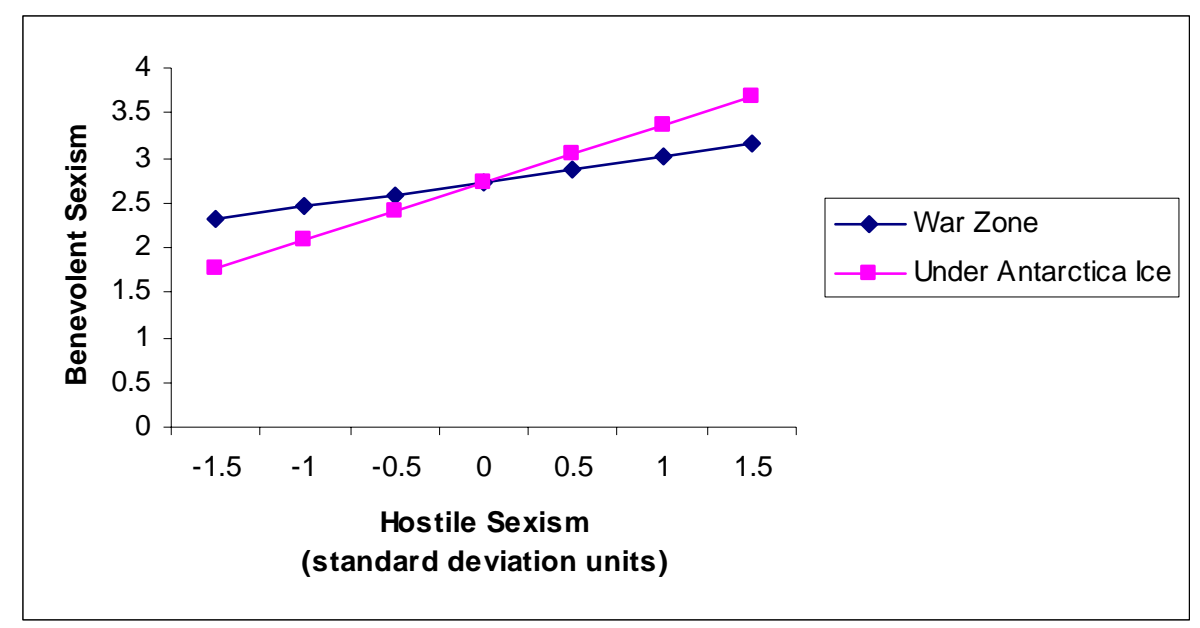

Figure 3: Interaction Effect between Hostile Sexism and Film Condition on Benevolent Sexism

Research on ambivalent sexism has found that hostile and benevolent sexism are usually positively correlated with each other, although some contrary findings have been found for older men, people who are more hostile towards women, and for those scoring higher in sexism (Glick \& Fiske, 1996, 2001). The disparate relationship between hostile and benevolent sexism between film conditions was therefore investigated by grouping participants into high and low hostility toward women to determine if the correlation between hostile and benevolent sexism differed within each film condition and between high and low hostile men. A median split was used to divide men into high and low hostility toward women, and the outlier previously mentioned was removed. The correlation between hostile and benevolent sexism was consistently a bit smaller in the high hostile groups, although the sample size would not permit an analysis of a potential interaction (see Table 9). As expected, the correlations for the War Zone condition were smaller than the comparison condition, and not statistically significant. 
Table 9: Intercorrelations between Hostile and Benevolent Sexism Based on Levels of Hostility Toward Women and Sexism $(N=81)$

\section{Hostility Toward Women $\quad \underline{r}$}

War Zone

Low HTW

High HTW

Under Antarctica Ice

Low HTW

High HTW
$.71^{*}$

$.55^{*}$

\section{Sexism}

War Zone

Low sexism $\quad-.11$

High sexism - $\quad$-.54*

Under Antarctica Ice

Low sexism $\quad .41^{\mathrm{a}}$

High sexism $\quad-.01$

Note: ${ }^{*} p<.05,{ }^{\mathrm{a}} p=.06$

The relationship between hostile and benevolent sexism was also investigated by grouping men by high and low sexism (using ambivalent sexism scores comprised of both hostile and benevolent sexism scores) to determine if the correlation between hostile and benevolent sexism differed within each film condition and between high and low sexists. A median split was used to divide men into high and low sexism. High sexists in the comparison group had no correlation between hostile and benevolent sexism, whereas high sexists in the War Zone group had a strong, negative, and significant correlation. In both the War Zone and comparison condition, men who were low on sexism did not show 
a statistically significant correlation, although this relationship did approach significance for the comparison group.

\section{Men's Description of War Zone}

Participants were asked to describe what the movie was about. Men’s responses to the question for the War Zone film were categorized into two groups: men whose responses included a reference to women's experience of sexual harassment on the street and how that behavior is often a negative experience for women (group 1), and men who did not include those characteristics in their description or were unclear in their description (group 2; see Table 10).

Table 10: Men's Responses to the Question “Describe What This Movie is About” ( $n=$ 40)

\section{Group 1}

1) This film is about a woman expressing her view and opinion on how men treat women in normal every-day situations in a generally negative manner.

2) Sexual predation of males on females. Stories of women and their negative experiences with men. Story of a woman (documentor) who asks men why they look, say, etc., what they say (do) to women.

3) This movie is about harassment toward women and the women's response toward this particular behavior. It shows that women are not safe and have to always be on the look-out.

4) The movie was about a woman who had been a victim of sexual harassment and went around with a camera trying to make men feel uncomfortable by interviewing them and asking them why they said what they said and did what they did to women.

5) This movie is about a woman's feeling toward men while they are being looked at by strangers.

6) Essentially it was to show how women feel on the street when faced with male aggression and further, to show where these feelings come from (high incidences 
of rape). It shows that women are not safe by themselves on the street in most major cities/towns.

7) The movie War Zone was about sexual harassment on the streets that women have to deal with, such as remarks.

8) This movie is used to draw attention to the fact that women get extremely uncomfortable by everyday male advances, by shoving a camera in their face, she sort of puts men through the stares women suffer from daily.

9) This film was about men who "check out" women in the streets that they do not know. The narrator almost got raped as a child and is now threatened by every man whom she does not previously know.

10) This film is about a woman who is exploring why it is culturally acceptable for men to make comments or even engage in unsolicited touching with strange women.

11) This movie is a response to men making cat calls and unwanted looks on the street. The director turns the camera on men to make a point that it is unwanted and uncomfortable.

12) This movie is a women's view on how men make women feel unsafe by making rude remarks to strangers in a public setting.

13) I was an intense documentary showing the open advances men make toward women and the responses women give. It also showed how women really feel about such things.

14) The film shows the sexual attitudes/behaviors express to women in the public.

15) The movie is about how men respond when they see women on the street. The lady goes around and interviews different men to see why they treat women like that.

16) This movie illustrated how men can make women feel. It also attempted to correlate women's feeling of safety from a man in relation to the comments made.

17) A perceived cultural paradigm that most people accept and do not even realize, much less attempt to change. By letting the more lecherous men that she finds experience the same threatening feeling that she has often felt, the researcher is hoping to raise awareness to an inherent problem of equality. Unfortunately, the researcher commits the same fallacies of reification that are imposed upon her, damaging the persuasive value of the film, as she does not address all situations in reality. 
18) This film was about how men in an urban setting look and say sexist things to women on the street and how that makes them feel.

19) Sometimes women feel intimidated/threatened by men. The movie focused on remarks that some men make to women as they walk down the street or are in public in general.

20) This movie is a documentary on the fear women have regarding rape, in which, the main woman in the movie walks around the streets seeing how many men would say explicit, provocative things to her. When men did comment about her, she would take out a camera and microphone and interview them about the men's comments and reasoning for their actions.

21) The movie is about a woman's perspective on the way men make comments to them on the streets. It shows how men misconceive the way they portray themselves and their actions toward total strangers to them.

22) This movie is about the way women are harassed by men who are complete strangers to them and how it is not the right thing for a strange man to offend women in derogative manner.

23) How society puts their spin on the way women want to be harassed. Saying in other words, it's about everyday occurrences that women face because men are idiots. This is a man writing this, so I can easily say men have lost their chivalry.

24) This movie is about sexual harassment toward women.

25) Sexual harassment towards women. How men act towards women on the street and how the woman reacts to this.

26) A woman confronts men in the street concerning their behavior towards women. Her focus in the film is to address the double-standard concerning behavior and how some men try to protect and respect women while others are out to harm women.

27) Male sexual objectification of women and the harmful effects in can cause.

28) Men harassing women in the street.

29) Sexual harassment towards women. How men act towards women on the street and how the woman reacts to this.

30) This movie is about sexual harassment and men's attitudes towards women.

31) How men make women feel uncomfortable 
32) A film depicting a woman who interviews numerous males that make sexual harassment-like comments. Most of the males are threatened by the camera.

\section{Group 2}

33) I think this movie is very biased. The woman was attacking all those guys.

34) Sexual issues between men and women.

35) A woman who wanted to prove a point to men by being a complete bitch. It had no relevance to anything.

36) A woman goes up to men she sees in the street and asks them why the look at random women in a sexual way.

37) Its about a woman who interviews/harasses men because they gave a compliment or commented on a woman's body.

38) This movie was about women who have been abused by trying to make a stand against what they think is harassment.

39) A lady was harassed so she felt all men are dogs, so she made a movie about men harassing women.

40) 1) male-female nonverbal interactions, 2) sexual assault, 3) implications of nonverbal attraction

Hostile Attitudes Toward Women and Men's Appreciation for the Filmmaker's Approach

A review of men's responses to the question asking participants to describe what the film is about indicated that some men viewed the filmmaker's approach negatively (e.g., \#17), and sometimes hostilely (e.g., \#35). Negative perceptions of the filmmaker's approach may be related to hostile attitudes toward women as the confrontational style of the filmmaker may trigger men’s hostility. In fact, the participant with response number 35 had a score high on both hostility toward women and hostile sexism, specifically, greater than one standard deviation from the mean for both their group and all of the men 
in the study. I ran correlations between hostility toward women, hostile sexism, and the appreciation of the film question that asks whether men found the filmmaker's approach effective, to determine if hostile attitudes predicted men's reaction to the filmmaker's approach. For hostility toward women, $r=-.36, p=.02$, and for hostile sexism, $r=-.22$, $p$ $=.17$.

\section{DISCUSSION}

This study was an experimental study to examine the impact of War Zone on men's attitudes related to street harassment. The most important finding is the absence of findings. Men who viewed War Zone did not have higher empathy for women who experience street harassment and lower acceptance of street harassment than men in the comparison condition. One reason why the film was not effective in changing men's attitudes may be because of the confrontational approach of the filmmaker. She purposely confronts men on the street who have engaged in some form of street harassment and questions them about their behavior, which may be perceived as annoying or hostile, and possibly elicits a defensive response from men. Overall men rated the content of the film as more valuable than the overall utility of the film in changing men's attitudes toward street harassment, suggesting that men may be interested in learning about the topic of street harassment, but not inclined toward the manner in which this film addresses the issue. One viewer’s comment demonstrates this possibility. He said, “...the researcher is hoping to raise awareness to an inherent problem of equality. Unfortunately, the researcher commits the same fallacies of reification that are imposed upon her, damaging the persuasive value of the film, as she does not address all situations in reality”. 
It is also possible that I did not find any group differences in the intermediate outcomes of empathy and acceptance because I collected data on attitudes immediately after the film whereas participants may need time to reflect on the material presented. Longer follow-up times may reveal a different pattern in the data. Relatedly, the film was shown to men with no consequent discussion about the material that would occur if the film were to be used as a component of a street harassment prevention effort. A discussion led by a peer may provide the necessary counterpart to the film for it to be useful in affecting attitudes toward street harassment. Finally, a one time intervention may simply not be enough to change attitudes that have been built and supported through many years of socialization.

Although the hypotheses regarding the impact of War Zone on empathy were not supported, the findings do support the importance of empathy in acceptance of street harassment. Cognitive empathy was related to acceptance across groups such that the more men perceive the experience as negative for women, the less acceptable they find street harassment. The lack of relationships between distress and acceptance, and sympathy and acceptance, suggest that affective states do not necessarily need to accompany cognitive empathy for street harassment to be considered unacceptable. This finding bodes well for future prevention in that it may be easier to inform people of the adverse consequences of street harassment for women than to affect men's emotional reaction to women's experience of street harassment.

The findings also support the importance of hostile attitudes toward women in men’s empathy. Men who were more hostilely sexist were significantly less likely to perceive women's negative experience of street harassment, and men who were more 
hostile toward women were significantly less likely to feel distressed in response to a woman being street harassed. A lack of cognitive empathy in hostile men may help justify the demonstration of power exhibited in street harassment behavior by minimizing the impact the behavior has on the woman. A lack of distress may be felt because the behavior is essentially justified.

Although the hypothesis regarding the impact of War Zone on acceptance was not supported, the findings do support the importance of peers attitudes or behaviors in acceptance of street harassment. As men's acceptance increased, so did their peer acceptance, suggesting that men are influenced by their peer’s attitudes. Social learning theory may explain why men share similar attitudes with their peers (Bandura, 1977). The theory asserts that people learn and enact behaviors through a process of observation and perceived or experienced reinforcement for engaging in the behavior. Men may observe their peers or other men engaging in street harassment and perceive the behavior as rewarding (e.g., fun, empowering) for the man engaging in the behavior and will thus be more likely to engage in the behavior himself.

Concurrently, social norms theory predicts that even if men do not think the behavior is acceptable or particularly rewarding in itself, they may still feel pressured to conform to the behavior of a peer group that does support the behavior. Social norms theory asserts that people often engage in certain behaviors because they are concerned about fitting into social norms, or perceived social norms (Baer, Stacy, \& Larimer, 1991). Research indicates that people frequently misperceive, and overestimate their peer’s beliefs and attitudes with regards to a variety of high risk and sexual behaviors (Scholly, Katz, Gascoigne, \& Holck, 2005) and that men often overestimate other men’s adherence 
to sexist beliefs and attitudes that promote sexual aggression (Fabiano, Perkins, Berkowitz, Linkenbach, \& Stark, 2003). Further, research has demonstrated that hypermasculine environments are more conducive to sexually aggressive behavior (Humphrey \& Kahn, 2000) and that men are more likely to engage in sexually aggressive behavior when they receive support for the behavior from their peers (DeKeseredy \& Kelly, 1995).

In this study, men’s acceptance not only positively correlated with peer acceptance, but men also consistently reported that their peers find street harassment more acceptable. While it may be true that the participants in this study have peers who are more accepting than the participants themselves of street harassment, these differences may simply reflect social desirability on the part of the participants as men may feel more comfortable endorsing the acceptability of street harassment when they are talking about their peer's beliefs rather than their own. However, these data may also reflect that men misperceive and over-inflate their peers' acceptance of street harassment, which could influence men to engage in the behavior.

The importance of men's peer groups also points to the relevance of exploring contextual variables that may influence street harassment as attitudes may vary depending on a variety of ethnic, cultural, and social attributes. While this sample does reflect some ethnic diversity, it is a small group of primarily Caucasian and AfricanAmerican college educated men. Such a group is sufficient for beginning to explore attitudes toward street harassment and possible avenues for prevention, but future research should examine the relevance of these findings to other social and cultural groups. 
A number of other findings emerged from the data that were not hypothesized but do help inform the nature of men's attitudes toward street harassment and responsiveness to the film. For one, hostile attitudes toward women were related to acceptance of street harassment such that as men's hostility increased, so did their acceptance of street harassment. As explained in theories of how hostility toward women may impact sexually aggressive behavior, it is possible that engaging in street harassment can give men who believe relationships with women are adversarial and potentially disempowering a sense of power over women by engaging with them on the street in this manner (Malamuth et al., 1995). Thus, hostile men may be more likely to engage in or be supportive of street harassment.

Further exploration into men's responses on the acceptance measure demonstrated that a set of myths about street harassment may exist similar to myths about sexual assault. Specifically, participants were more willing to accept street harassment behavior under certain conditions. They tended to agree that street harassment is not acceptable when women are with their children or other men, although the behavior becomes much more acceptable when women are dressed in sexy clothing, make eye contact with men, or smile at men. This pattern of responses suggests that women who are unaccompanied by men, not engaged in traditional female roles, and perceived as sexually inviting are in some way inviting street harassment behavior, which are beliefs that mirror commonlyheld misconceptions about rape (e.g., rape myths; Burt, 1980). Rape myths serve the purpose of justifying sexual victimization by claiming that women are responsible for the behavior as a consequence of behaviors they do or not do (e.g., wear revealing clothing, get drunk, go out late at night). Similar to sexual assault prevention, street harassment 
prevention efforts may benefit from debunking these "street harassment myths" and increasing men’s cognitive empathy.

Another surprising, although not hypothesized finding, was that War Zone appeared to impact the participants’ sexist views of women. Specifically, the War Zone group had a smaller positive correlation between hostile and benevolent sexism than the comparison group, which may be caused by a polarization of views for sexist men. Further investigation into the relationship between hostile and benevolent sexism was done following the findings of Glick \& Fiske (2001) in which highly sexist men did not demonstrate a positive correlation between hostile and benevolent sexism. In my study, when comparing the relationship between hostile and benevolent sexism for highly sexist men in both groups, highly sexist men in the War Zone group reported a strong negative correlation indicating that as their hostile sexism increased, their benevolent sexism decreased.

The negative relationship between hostile and benevolent sexism for highly sexist men suggests that the film polarizes these men's views of women. Research suggests that when individuals are confronted with material addressing complex social issues, they often attend and give more weight to aspects of the material that support their preexisting view, resulting an increased polarization of their views on the issue (Lord, Ross, \& Lepper, 1979). After viewing War Zone, highly sexist men may perceive that all women are either "good” (represented by high scores on benevolent sexism and low scores on hostile sexism) or "bad" (represented by high scores on benevolent sexism and low scores on hostile sexism), depending on how they viewed the content and presentation of the film and their pre-existing inclination (hostile or benevolent). 
Polarization of one's attitudes toward women may make prevention around street harassment more difficult and suggests that War Zone be used to raise awareness of street harassment among men with caution.

\section{Summary}

In a diverse sample of college-educated men, War Zone does not appear to be effective in changing men's attitudes toward street harassment and may actually polarize men’s existing views about women. An impediment to the film's ability to change men's attitudes about street harassment may be that the message is coming from a woman and is often confrontational. Not only do men appear to be more receptive to other men on topics of sexual victimization (Berkowitz, 2002), but the woman in the film can be seen as taking back power from men (or exerting power over men with her camera), which may incite a more defensive stance, particularly for those men who have more hostile attitudes toward women.

Although War Zone does not appear to be effective in changing men’s attitudes toward street harassment, this study uncovered many interesting predictors of empathy and acceptance of street harassment which may inform future prevention efforts. The data suggest that increasing men's awareness of the often negative experiences and consequences of street harassment may be beneficial in decreasing men's acceptance of the behavior. However, the peer context is important to address since men may not believe that street harassment is acceptable but still feel compelled to engage in the behavior as a consequence of perceived peer group acceptance and associated masculine prescriptions. Any prevention effort should also attend to the potentially problematic 
nature of some men's hostile attitudes toward women, which may halt if not degrade any efforts to change attitudes toward street harassment. 


\section{REFERENCES}

Abbey, A., McAuslan, P., Zawacki, T., Clinton, A. M., \& Buck, P. O. (2001). Attitudinal, experiential and situational predictors of sexual assault perpetration. Journal of Interpersonal Violence, 16(8), 784-807.

Abrams, D., Viki, G. T., Masser, B., \& Bohner, G. (2003). Perceptions of stranger and acquaintance rape: The role of benevolent and hostile sexism in victim blame and rape proclivity. Journal of Personality and Social Psychology, 84(1), 111-125.

Allison, P. (2001). Missing data. Thousand Oaks: Sage.

Angelone, D. J., Hirschman, R., Suniga, S., Michael Armey, \& Armelie, A. (2005). The influence of peer interactions on sexually oriented joke telling. Sex Roles, 52(3/4), 187-199.

Baer, J. S., Stacy, A., \& Larimer, M. (1991). Biases in the perception of drinking norms among college students. Journal of Studies on Alcohol, 52(6), 580-586.

Bandura, A. (1977). Social Learning Theory. Englewood Cliffs, NJ: Prentice-Hall.

Baron, R. M., \& Kenny, D. A. (1986). The moderator-mediator variable distinction in social psychological research: Conceptual, strategic, and statistical considerations. Journal of Personality and Social Psychology, 51(6), 1173-1182.

Baston, C. D., O'Quin, K., Fultz, J., Vanderplas, M., \& Isen, A. M. (1983). Influence of self-reported distress and empathy on egoistic versus altruistic motivation to help. Journal of Personality and Social Psychology, 45(3), 706-718.

Begany, J. J., \& Milburn, M. A. (2002). Psychological predictors of sexual harassment: Authoritarianism, hostile sexism, and rape myths. Psychology of Men and Masculinity, 3(2), 119-126. 
Berkowitz, A. D. (2002). Fostering men's responsibility for preventing sexual assault. In P. A. Schewe (Ed.), Preventing violence in relationships (pp. 163-196). Washington, D.C.: American Psychological Association.

Board of Regents of the University System of Georgia. (2004). Semester enrollment report. Atlanta, Georgia.

Boeringer, S. B. (1999). Associations of rape-supportive attitudes with fraternal and athletic participation. Violence Against Women, 5(1), 81-90.

Bowman, C. G. (1993). Street harassment and the informal ghettoization of women. Harvard Law Review, 106(3), 517-580.

Brecklin, L. R., \& Forde, D. R. (2001). A meta-analysis of rape education programs. Violence and Victims, 16(3), 303-321.

CampusActivism. (2002). CampusActivism calendar: War Zone - Film screening and lecture with Maggie Hadleigh-West. Retrieved February 15, 2005, from http://www.campusactivism.org/displayevent-7.htm

Caron, S. L., \& Carter, D. B. (1997). The relationships among sex role orientation, egalitarianism, attitudes toward sexuality, and attitudes toward violence against women. The Journal of Social Psychology, 137(5), 568-587.

Check, J. V. P., Malamuth, N. M., Elias, B., \& Barton, S. (1985). On hostile ground. Psychology Today, April(56-61).

Cohen, J., \& Cohen, P. (1983). Applied multiple regression /correlation analysis for the behavioral sciences (2 ed.). Mahwah, New Jersey: Lawrence Erlbaum Associates, Inc. 
Davis, M. H. (1994). Empathy: A social psychological approach. Dubuque, IA: Brown \& Benchmark.

DeKeseredy, W. S., \& Kelly, K. (1995). Sexual abuse in Canadian university and college dating relationships: The contribution of male peer support. Journal of Family Violence, 10(1), 41-53.

Fabiano, P. M., Perkins, W., Berkowitz, A., Linkenbach, J., \& Stark, C. (2003). Engaging men as social justice allies in ending violence against women: Evidence for a social norms approach. Journal Of American College Health, 52(3), 105-112.

Fernandez, Y. M., \& Marshall, W. L. (2003). Victim empathy, social self-esteem, and psychopathy in rapists. Sexual Abuse: A Journal of Research and Treatment, 15(1), 11-26.

Forbes, G. B., Adams-Curtis, L. E., \& White, K. B. (2004). First- and second-generation measures of sexism, rape myths and related beliefs, and hostility toward women: Their interrelationships and association with college students' experiences with dating aggression and sexual coercion. Violence Against Women, 10(3), 236-261.

Gardner, C. B. (1995). Passing by: Gender and public harassment. Berkeley, California: University of California Press.

Glick, P., \& Fiske, S. T. (1996). The Ambivalent Sexism Inventory: Differentiating hostile and benevolent sexism. Journal of Personality and Social Psychology, 70(3), 503-517.

Glick, P., \& Fiske, S. T. (2001). An ambivalent alliance: Hostile and benvolent sexism as complementary justifications for gender inequality. American Psychologist, 56(2), 109-118. 
Goodchilds, J. D., \& Zellman, G. (1984). Sexual signaling and sexual aggression in adolescents and their perceptions of sexual interaction. In N. Malamuth \& E. Donnerstein (Eds.), Pornography and sexual aggression (pp. 234-243). Orlando: Academic Press.

Hadleigh-West, M. (1998). War Zone [Documentary]. New York: Film Fatale Productions.

Humphrey, S. E., \& Kahn, A. S. (2000). Fraternities, athletic teams, and rape. Journal of Interpersonal Violence, 15(12), 1313 - 1322.

Koss, M. P., Goodman, L. A., Browne, A., Fitzgerald, L. F., Keita, G. P., \& Russo, N. F. (1994). No safe haven: Male violence against women at home, at work, and in the community. Washington, D.C.: American Psychological Association.

Lenton, R., Smith, M. D., Fox, J., \& Morra, N. (1999). Sexual harassment in public places: Experiences of Canadian women. CRSA/RCSA, 36(4), 517-540.

Lonsway, K. A., \& Fitzgerald, L. F. (1994). Rape myths: In review. Psychology of Women Quarterly, 18, 133-164.

Lonsway, K. A., \& Fitzgerald, L. F. (1995). Attitudinal antecedents of rape myth acceptance: A theoretical and empirical reexamination. Journal of Personality and Social Psychology, 68(4), 704-711.

Lord, C. G., Ross, L., \& Lepper, M. R. (1979). Biased assimilation and attitude polarization: The effects of prior theories on subsequently considered evidence. Journal of Personality and Social Psychology, 37(11), 2098-2109. 
MacMillan, R., Nierobisz, A., \& Welsh, S. (2000). Experiencing the streets: Harassment and perceptions of safety among women. Journal of Research in Crime and Delinquency, 37(3), 306-322.

Malamuth, N. M., Linz, D., Heavey, C. L., Barnes, G., \& Acker, M. (1995). Using the confluence model of sexual aggression to predict men's conflict with women: A 10-year follow-up study. Journal of Personality and Social Psychology, 69(2), 353-369.

Marshall, W. L., Hudson, S. M., Jones, R., \& Fernandez, Y. M. (1995). Empathy in sex offenders. Clinical Psychology Review, 15(2), 99-113.

Marshall, W. L., \& Moulden, H. (2001). Hostility toward women and victim empathy in rapists. Sexual Abuse: A Journal of Research and Treatment, 13(4), 249-255.

Murnen, S. K., Wright, C., \& Kaluzny, G. (2002). If "boys will be boys," then girls will be victims? A meta-analytic review of the research that relates masculine ideology to sexual aggression. Sex Roles, 46(11/12), 359-375.

O'Donohue, W., Downs, K., \& Yeater, E. A. (1998). Sexual harassment: A review of the literature. Aggression and Violent Behavior, 3(2), 111-128.

O'Donohue, W., Yeater, E. A., \& Fanetti, M. (2003). Rape prevention with college males: The roles of rape myth acceptance, victim empathy, and outcome expectancies. Journal of Interpersonal Violence, 18(5), 513-531.

Quina, K. (1990). Sexual harassment and rape: A continuum of exploitation. In M. A. Paludi (Ed.), Sexual harassment on college campuses (pp. 183-197). Albany, NY: State University of New York Press. 
Quinn, B. A. (2002). Sexual harassment and masculinity: The power and meaning of "girl watching". Gender \& Society, 16(3), 386-402.

Russell, B. L., \& Trigg, K. Y. (2004). Tolerance of sexual harassment: An examination of gender differences, ambivalent sexism, social dominance, and gender roles. Sex Roles, 50(7/8), 565573.

Scholly, K., Katz, A. R., Gascoigne, J., \& Holck, P. S. (2005). Using social norms theory to explain perceptions and sexual health behaviors of undergraduate college students: An exploratory study. Journal Of American College Health, 53(4), 159166.

Stephens, K. A., \& George, W. H. (2004). Effects of anti-rape video content on sexually coercive and noncoercive college men's attitudes and alcohol expectancies. Journal of Applied Social Psychology, 34(2), 402-416.

The Street Harassment Project. (2005). Retrieved February, 2005, from www.streetharassmentproject.org

Winkel, F. W., \& de Kleuver, E. (1997). Communication aimed at changing cognitions about sexual intimidation: Comparing the impact of a perpetrator-focused versus a victim-focused persuasive strategy. Journal of Interpersonal Violence, 12(4), 513-529. 


\section{APPENDIX}

Measures

\section{Demographics: (Administered Last)}

Please answer the following questions. If you do not feel comfortable answering a question, you may leave it blank.

1) What is your age? (years)

2) What is your relationship status?

single
dating in non-committed relationship
in a committed relationship

3) What is your year in school? $\left(1^{\text {st }}, 2^{\text {nd }}, 3^{\text {rd }}\right.$ etc. $)$

4) How many years have you been at GSU?

5) What is your sexual orientation? (please write in the blank space provided)

6) What is your race/ethnicity? (choose one)

$\ldots$ African-American
$\ldots$ Latino/a
Caucasian
East Asian
South Asian
Multiracial (specify: $\_$)


Appreciation for the Film - War Zone

Please describe what this movie is about:

Please share your opinions about the film by answering the questions below.

Valuable $=$ useful and important

Effective = help get the film's message across

\begin{tabular}{|l|l|c|c|c|c|c|}
\hline 1) & $\begin{array}{l}\text { Is not } \\
\begin{array}{l}\text { Do you think the film's } \\
\text { content is valuable } \\
\text { (what the film is about and } \\
\text { what it had to say)? }\end{array}\end{array}$ & 1 & 2 & 3 & $\begin{array}{c}\text { Quite a } \\
\text { bit }\end{array}$ & Extremely \\
\hline 2) & $\begin{array}{l}\text { Do you think the film's } \\
\text { cinematography (e.g., } \\
\text { documentary-style, } \\
\text { color/black \& white) } \\
\text { and music is effective? }\end{array}$ & 1 & 2 & 3 & 4 & 5 \\
\hline 3$)$ & $\begin{array}{l}\text { Do you think the } \\
\text { filmmaker's approach is } \\
\text { effective (how the } \\
\text { filmmaker “told the } \\
\text { story")? }\end{array}$ & 1 & 2 & 3 & 4 & 5 \\
\hline 4$)$ & $\begin{array}{l}\text { Do you think this film } \\
\text { would be useful in } \\
\text { changing men's attitudes } \\
\text { about street harassment? }\end{array}$ & 1 & 2 & 3 & 4 & 5 \\
\hline
\end{tabular}


Appreciation for the Film - Under Antarctica Ice

Please describe what this movie is about:

Please share your opinions about the film by answering the questions below.

Valuable $=$ useful and important

Effective = help get the film's message(s) across

\begin{tabular}{|l|l|c|c|c|c|c|}
\hline & Is not & A little & Somewhat & $\begin{array}{c}\text { Quite a } \\
\text { bit }\end{array}$ & Extremely \\
\hline 1) & $\begin{array}{l}\text { Do you think the film's } \\
\text { content is valuable } \\
\text { (what the film is about and } \\
\text { what it had to say)? }\end{array}$ & 1 & 2 & 3 & 4 & 5 \\
\hline 2) & $\begin{array}{l}\text { Do you think the film's } \\
\text { cinematography is } \\
\text { effective? }\end{array}$ & 1 & 2 & 3 & 4 & 5 \\
\hline 3$)$ & $\begin{array}{l}\text { Do you think the } \\
\text { filmmakers' approach is } \\
\text { effective (how the } \\
\text { filmmakers “told the } \\
\text { story")? }\end{array}$ & 1 & 2 & 3 & 4 & 5 \\
\hline 4) & $\begin{array}{l}\text { Do you think this film } \\
\text { would useful in teaching } \\
\text { about life in the ocean } \\
\text { under the ice in Antarctica? }\end{array}$ & 1 & 2 & 3 & 4 & 5 \\
\hline
\end{tabular}


Hostility Toward Women Scale (HTWS)

Please circle the appropriate number:

\begin{tabular}{|c|c|c|c|c|c|c|c|c|}
\hline & & Agre & & & & & & Disagree \\
\hline 1) & $\begin{array}{l}\text { I feel that many times } \\
\text { women flirt with men } \\
\text { just to tease them or hurt } \\
\text { them. }\end{array}$ & 1 & 2 & 3 & 4 & 5 & 6 & 7 \\
\hline 2) & $\begin{array}{l}\text { I believe that most } \\
\text { women tell the truth. }\end{array}$ & 1 & 2 & 3 & 4 & 5 & 6 & 7 \\
\hline 3) & $\begin{array}{l}\text { I usually find myself } \\
\text { agreeing with women. }\end{array}$ & 1 & 2 & 3 & 4 & 5 & 6 & 7 \\
\hline 4) & $\begin{array}{l}\text { I think that most women } \\
\text { would lie just to get } \\
\text { ahead. }\end{array}$ & 1 & 2 & 3 & 4 & 5 & 6 & 7 \\
\hline 5) & $\begin{array}{l}\text { Generally, it is safer not } \\
\text { to trust women. }\end{array}$ & 1 & 2 & 3 & 4 & 5 & 6 & 7 \\
\hline 6) & $\begin{array}{l}\text { When it really comes } \\
\text { down to it, a lot of } \\
\text { women are deceitful. }\end{array}$ & 1 & 2 & 3 & 4 & 5 & 6 & 7 \\
\hline 7) & $\begin{array}{l}\text { I am easily angered by } \\
\text { women. }\end{array}$ & 1 & 2 & 3 & 4 & 5 & 6 & 7 \\
\hline 8) & $\begin{array}{l}\text { I am sure I get a raw } \\
\text { deal from the women in } \\
\text { my life. }\end{array}$ & 1 & 2 & 3 & 4 & 5 & 6 & 7 \\
\hline 9) & $\begin{array}{l}\text { Sometimes women } \\
\text { bother me just by being } \\
\text { around. }\end{array}$ & 1 & 2 & 3 & 4 & 5 & 6 & 7 \\
\hline 10) & $\begin{array}{l}\text { Women are responsible } \\
\text { for most of my troubles. }\end{array}$ & 1 & 2 & 3 & 4 & 5 & 6 & 7 \\
\hline
\end{tabular}




\section{Ambivalent Sexism Inventory (ASI)}

Below is a series of statements concerning men and women and their relationships in contemporary society. Please indicate the degree to which you agree or disagree with each statement using the following scale:

$\begin{array}{cccccc}0 & 1 & 2 & 3 & 4 & 5 \\ \begin{array}{l}\text { Disagree } \\ \text { strongly }\end{array} & \text { Disagree } & \text { Disagree } & \text { Agree } & \text { Agree } & \text { Agree } \\ \text { somewhat } & \text { slightly } & \text { slightly } & \text { Somewhat } & \text { strongly }\end{array}$

1. No matter how accomplished he is, a man is not truly complete as a person unless he has the love of a woman.

2. Many women are actually seeking special favors, such as hiring policies that favor them over men, under the guise of asking for "equality."

3. In a disaster, women ought not necessarily be rescued before men.

4. Most women interpret innocent remarks or acts as being sexist.

5. Women are too easily offended.

6. People are often truly happy in life without being romantically involved with a member of the other sex.

7. Feminists are not seeking for women to have more power than men.

8. Many women have a quality of purity that few men possess.

9. Women should be cherished and protected by men.

10. Most women fail to appreciate fully all that men do for them.

11. Women seek to gain power by getting control over men.

12. Every man ought to have a woman whom he adores.

13. Men are complete without women.

14. Women exaggerate problems they have at work.

15. Once a woman gets a man to commit to her, she usually tries to put him on a tight leash.

16. When women lose to men in a fair competition, they typically complain about being discriminated against.

17. A good woman should be set on a pedestal by her man.

18. There are actually very few women who get a kick out of teasing men by seeming sexually available and then refusing male advances.

19. Women, compared to men, tend to have a superior moral sensibility.

20. Men should be willing to sacrifice their own well being in order to provide financially for the women in their lives.

21. Feminists are making entirely reasonable demands of men.

22. Women, as compared to men, tend to have a more refined sense of culture and good taste. 


\section{Empathy: Perspective-Taking (REM)}

A woman is walking down the street when she hears a man that she does not know whistle at her and say "nice ass".

On a scale from 0 to 10 , how much you think this woman feels the following feelings?

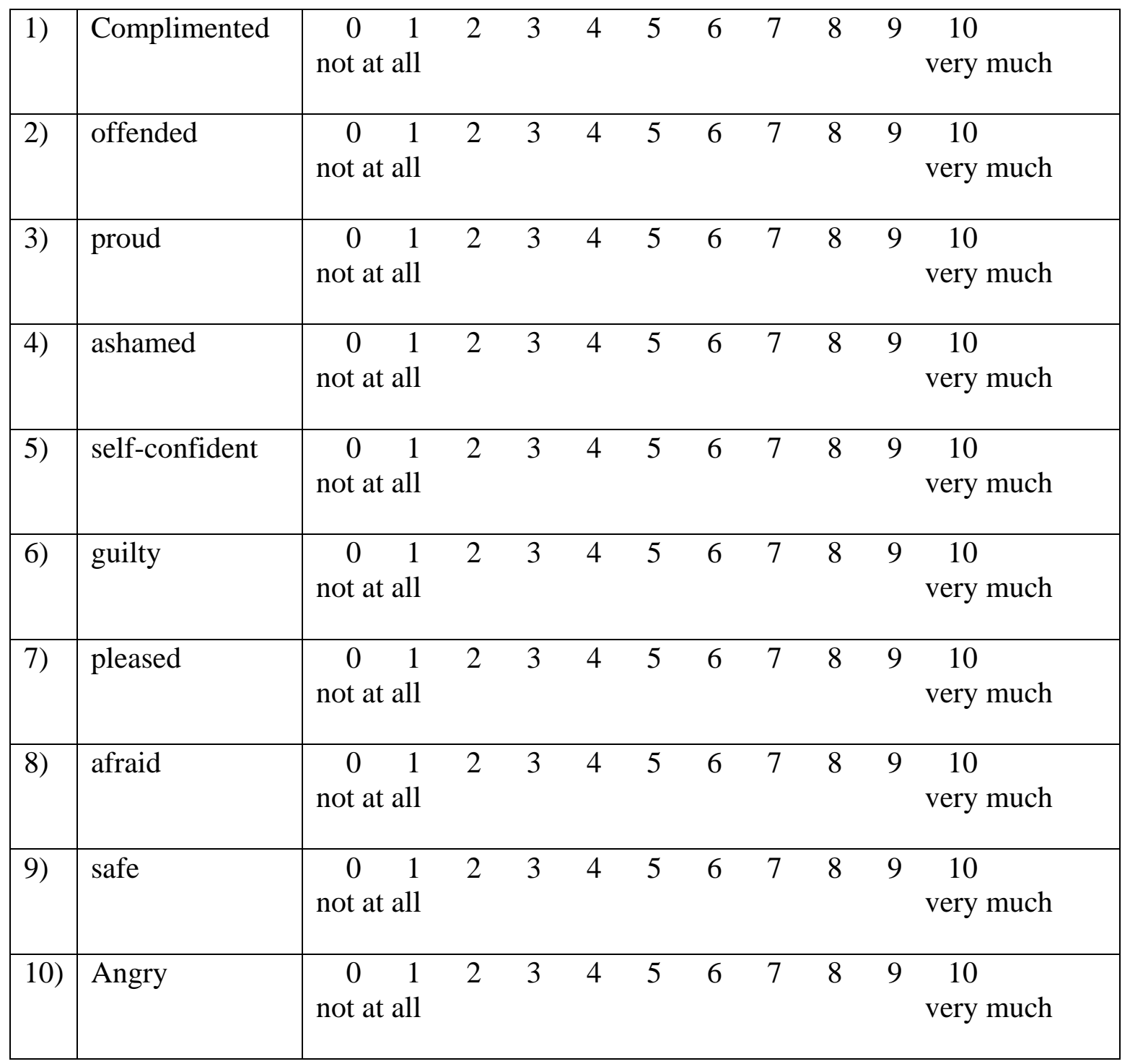




\section{Emotional ResponseQuestionnaire (ERQ)}

A woman is walking down the street when she hears a man that she does not know whistle at her and say "nice ass".

How much do you feel the following?

\begin{tabular}{|l|l|c|c|c|c|c|c|c|}
\hline & & \multicolumn{3}{|c|}{ Not at all } \\
\hline 1$)$ & Alarmed & 1 & 2 & 3 & 4 & 5 & 6 & 7 \\
\hline 2$)$ & Sympathetic & 1 & 2 & 3 & 4 & 5 & 6 & 7 \\
\hline 3$)$ & Grieved & 1 & 2 & 3 & 4 & 5 & 6 & 7 \\
\hline 4$)$ & Moved & 1 & 2 & 3 & 4 & 5 & 6 & 7 \\
\hline 5$)$ & Upset & 1 & 2 & 3 & 4 & 5 & 6 & 7 \\
\hline 6$)$ & Worried & 1 & 2 & 3 & 4 & 5 & 6 & 7 \\
\hline 7$)$ & Compassionate & 1 & 2 & 3 & 4 & 5 & 6 & 7 \\
\hline 8$)$ & Disturbed & 1 & 2 & 3 & 4 & 5 & 6 & 7 \\
\hline 9$)$ & Tender & 1 & 2 & 3 & 4 & 5 & 6 & 7 \\
\hline 10$)$ & Perturbed & 1 & 2 & 3 & 4 & 5 & 6 & 7 \\
\hline 11$)$ & Warm & 1 & 2 & 3 & 4 & 5 & 6 & 7 \\
\hline 12$)$ & Distressed & 1 & 2 & 3 & 4 & 5 & 6 & 7 \\
\hline 13$)$ & Softhearted & 1 & 2 & 3 & 4 & 5 & 6 & 7 \\
\hline 14$)$ & Troubled & 2 & 3 & 4 & 5 & 6 & 7 \\
\hline
\end{tabular}




\section{Acceptance of Street Harassment}

How acceptable do you think it is for a man to make an unsolicited, unreciprocated, and unnecessary comment toward an unknown woman on the street (for example; saying “hey baby” or “nice ass”)?

\begin{tabular}{|c|c|c|c|c|c|c|}
\hline & & $\begin{array}{l}\text { Not at all } \\
\text { acceptable }\end{array}$ & & & & ptable \\
\hline 1) & When she is attractive & 1 & 2 & 3 & 4 & 5 \\
\hline 2) & $\begin{array}{l}\text { When she is dressed in sexy } \\
\text { clothing } \\
\text { (e.g., short skirt, tight } \\
\text { clothes) }\end{array}$ & 1 & 2 & 3 & 4 & 5 \\
\hline 3) & $\begin{array}{l}\text { When she makes eye contact } \\
\text { with him }\end{array}$ & 1 & 2 & 3 & 4 & 5 \\
\hline 4) & When she smiles at him & 1 & 2 & 3 & 4 & 5 \\
\hline 5) & When she is alone & 1 & 2 & 3 & 4 & 5 \\
\hline 6) & When she is with her friends & 1 & 2 & 3 & 4 & 5 \\
\hline 7) & When she is with a man & 1 & 2 & 3 & 4 & 5 \\
\hline 8) & $\begin{array}{l}\text { When she is with her } \\
\text { children }\end{array}$ & 1 & 2 & 3 & 4 & 5 \\
\hline 9) & When he is alone & 1 & 2 & 3 & 4 & 5 \\
\hline 10) & When he is with his friends & 1 & 2 & 3 & 4 & 5 \\
\hline 11) & $\begin{array}{l}\text { When he is in an unfamiliar } \\
\text { neighborhood }\end{array}$ & 1 & 2 & 3 & 4 & 5 \\
\hline
\end{tabular}


How acceptable do you think it is for a man to engage in unsolicited, unreciprocated, and unnecessary touching of an unknown woman on the street (grabbing a woman's buttocks, or brushing up purposely against a woman)?

\begin{tabular}{|c|c|c|c|c|c|c|}
\hline & & $\begin{array}{l}\text { Not at all } \\
\text { acceptable }\end{array}$ & & & & ptable \\
\hline 1) & When she is attractive & 1 & 2 & 3 & 4 & 5 \\
\hline 2) & $\begin{array}{l}\text { When she is dressed in sexy } \\
\text { clothing } \\
\text { (e.g., short skirt, tight } \\
\text { clothes) }\end{array}$ & 1 & 2 & 3 & 4 & 5 \\
\hline 3) & $\begin{array}{l}\text { When she makes eye contact } \\
\text { with him }\end{array}$ & 1 & 2 & 3 & 4 & 5 \\
\hline 4) & When she smiles at him & 1 & 2 & 3 & 4 & 5 \\
\hline 5) & When she is alone & 1 & 2 & 3 & 4 & 5 \\
\hline 6) & When she is with her friends & 1 & 2 & 3 & 4 & 5 \\
\hline 7) & When she is with a man & 1 & 2 & 3 & 4 & 5 \\
\hline 8) & $\begin{array}{l}\text { When she is with her } \\
\text { children }\end{array}$ & 1 & 2 & 3 & 4 & 5 \\
\hline 9) & When he is alone & 1 & 2 & 3 & 4 & 5 \\
\hline 10) & When he is with his friends & 1 & 2 & 3 & 4 & 5 \\
\hline 11) & $\begin{array}{l}\text { When he is in an unfamiliar } \\
\text { neighborhood }\end{array}$ & 1 & 2 & 3 & 4 & 5 \\
\hline
\end{tabular}




\section{Peer Acceptance of Street Harassment}

How acceptable do you think your FRIENDS think it is for a man to make an unsolicited, unreciprocated, and unnecessary comment toward an unknown woman on the street (for example; saying "hey baby” or “nice ass”)?

\begin{tabular}{|c|c|c|c|c|c|c|}
\hline & & \multicolumn{3}{|c|}{$\begin{array}{l}\text { Not at all } \\
\text { acceptable }\end{array}$} & \multicolumn{2}{|c|}{$\begin{array}{c}\text { Very } \\
\text { acceptable }\end{array}$} \\
\hline 1) & When she is attractive & 1 & 2 & 3 & 4 & 5 \\
\hline 2) & $\begin{array}{l}\text { When she is dressed in sexy } \\
\text { clothing } \\
\text { (e.g., short skirt, tight } \\
\text { clothes) }\end{array}$ & 1 & 2 & 3 & 4 & 5 \\
\hline 3) & $\begin{array}{l}\text { When she makes eye contact } \\
\text { with him }\end{array}$ & 1 & 2 & 3 & 4 & 5 \\
\hline 4) & When she smiles at him & 1 & 2 & 3 & 4 & 5 \\
\hline 5) & When she is alone & 1 & 2 & 3 & 4 & 5 \\
\hline 6) & When she is with her friends & 1 & 2 & 3 & 4 & 5 \\
\hline 7) & When she is with a man & 1 & 2 & 3 & 4 & 5 \\
\hline 8) & $\begin{array}{l}\text { When she is with her } \\
\text { children }\end{array}$ & 1 & 2 & 3 & 4 & 5 \\
\hline 9) & When he is alone & 1 & 2 & 3 & 4 & 5 \\
\hline 10) & When he is with his friends & 1 & 2 & 3 & 4 & 5 \\
\hline 11) & $\begin{array}{l}\text { When he is in an unfamiliar } \\
\text { neighborhood }\end{array}$ & 1 & 2 & 3 & 4 & 5 \\
\hline
\end{tabular}


How acceptable do you think your FRIENDS think it is for a man to engage in unsolicited, unreciprocated, and unnecessary touching of an unknown woman on the street (grabbing a woman's buttocks, or brushing up purposely against a woman)?

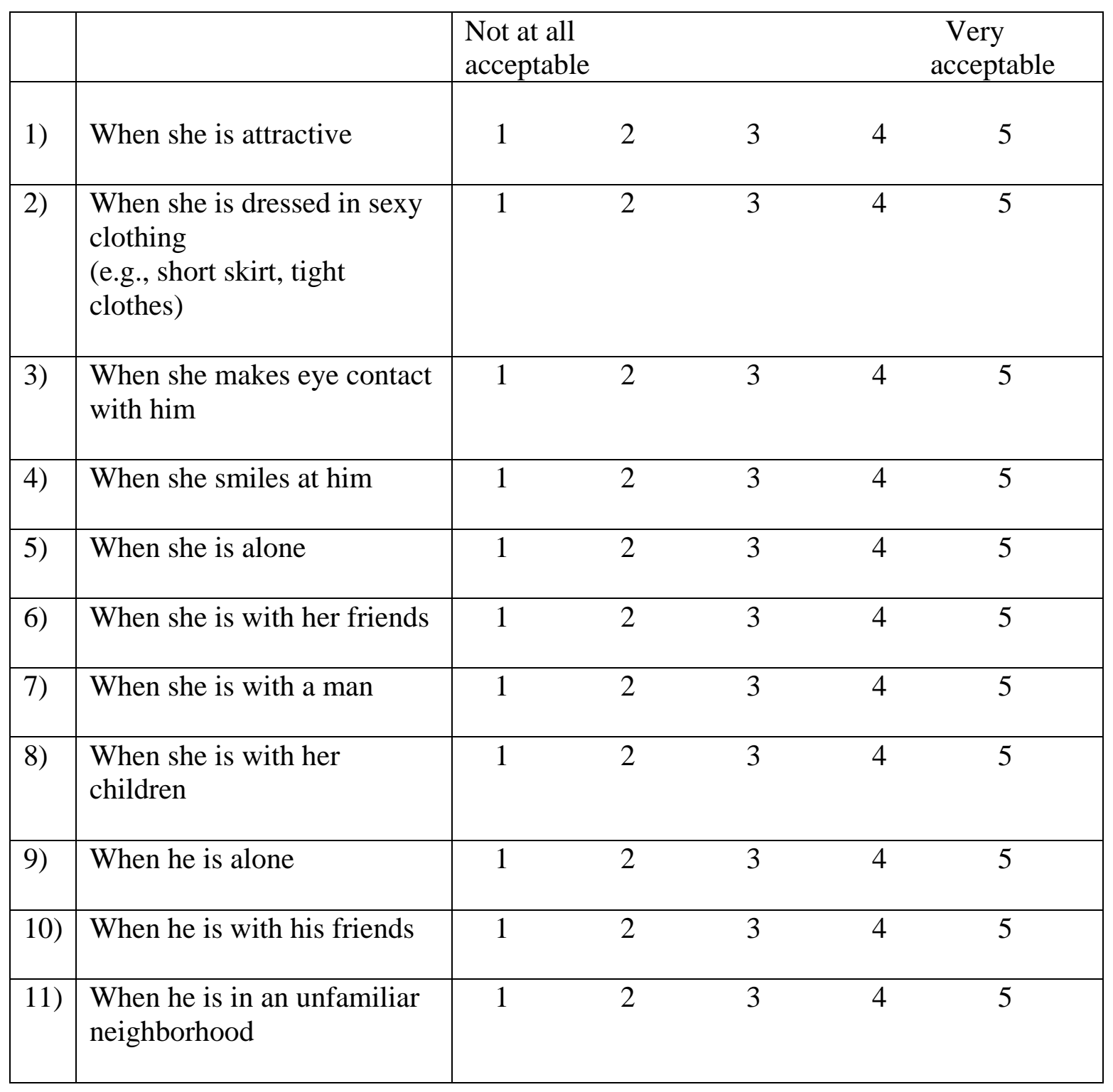

